\title{
Candidate genes and SNPs associated with stomatal conductance under drought stress in Vitis
}

Massimiliano Trenti ${ }^{*} \mathbb{D}$, Silvia Lorenzi ${ }^{1}$, Pier Luigi Bianchedi ${ }^{2}$, Daniele Grossi ${ }^{3}$, Osvaldo Failla ${ }^{3}$, Maria Stella Grando ${ }^{1,4^{*}}$ and Francesco Emanuelli $i^{1,3}$

\begin{abstract}
Background: Understanding the complexity of the vine plant's response to water deficit represents a major challenge for sustainable winegrowing. Regulation of water use requires a coordinated action between scions and rootstocks on which cultivars are generally grafted to cope with phylloxera infestations. In this regard, a genomewide association study (GWAS) approach was applied on an 'ad hoc' association mapping panel including different Vitis species, in order to dissect the genetic basis of transpiration-related traits and to identify genomic regions of grape rootstocks associated with drought tolerance mechanisms.

The panel was genotyped with the GrapeReSeq Illumina $20 \mathrm{~K}$ SNP array and SSR markers, and infrared thermography was applied to estimate stomatal conductance values during progressive water deficit.

Results: In the association panel the level of genetic diversity was substantially lower for SNPs loci (0.32) than for SSR (0.87). GWAS detected 24 significant marker-trait associations along the various stages of drought-stress experiment and 13 candidate genes with a feasible role in drought response were identified.

Gene expression analysis proved that three of these genes (VIT_13s0019g03040, VIT_1750000g08960, VIT_18s0001g15390) were actually induced by drought stress.

Genetic variation of VIT_17s0000g08960 coding for a raffinose synthase was further investigated by resequencing the gene of 85 individuals since a SNP located in the region (chr17_10,497,222_C_T) was significantly associated with stomatal conductance.
\end{abstract}

Conclusions: Our results represent a step forward towards the dissection of genetic basis that modulate the response to water deprivation in grape rootstocks. The knowledge derived from this study may be useful to exploit genotypic and phenotypic diversity in practical applications and to assist further investigations.

Keywords: Grapevine, Rootstocks, Drought stress, Genome-wide association study, Candidate gene

\footnotetext{
* Correspondence: massimiliano.trenti@fmach.it;

massimiliano.trenti88@gmail.com; stella.grando@unitn.it

${ }^{1}$ Research and Innovation Centre, Fondazione Edmund Mach, via E. Mach 1,

38010 San Michele all'Adige, Italy

Full list of author information is available at the end of the article
}

C C The Author(s). 2021 Open Access This article is licensed under a Creative Commons Attribution 4.0 International License, which permits use, sharing, adaptation, distribution and reproduction in any medium or format, as long as you give appropriate credit to the original author(s) and the source, provide a link to the Creative Commons licence, and indicate if changes were made. The images or other third party material in this article are included in the article's Creative Commons licence, unless indicated otherwise in a credit line to the material. If material is not included in the article's Creative Commons licence and your intended use is not permitted by statutory regulation or exceeds the permitted use, you will need to obtain permission directly from the copyright holder. To view a copy of this licence, visit http://creativecommons.org/licenses/by/4.0/ The Creative Commons Public Domain Dedication waiver (http://creativecommons.org/publicdomain/zero/1.0/) applies to the data made available in this article, unless otherwise stated in a credit line to the data. 


\section{Background}

Climate change is strongly influencing human life and natural systems $[1,2]$, having a drastic impact on agriculture worldwide, and so viticulture must also face these new environmental conditions. Drought is the factor, among abiotic stressors, which mostly affects plant physiology [3]. Therefore, understanding the complexity of the plant's response to water deficit poses a major challenge for researchers.

Grapevine is considered to be a relatively drought tolerant plant, thus the impact of climate change on viticulture sustainability is subject of lively debate [4-7]. Nevertheless, strategies to reduce water consumption and to improve water-use efficiency (WUE) in vines are fundamental for the future [8]. Water deficit strongly affects fruit quality and causes significant losses in crop yield. In particular, prolonged droughts could have consequences for the upcoming growing seasons [9] and may enhance susceptibility to biotic pests or pathogens [10].

Drought-stress response is the result of complex and dynamic physiological, biochemical and molecular processes at cellular and systemic levels. Water deficit leads to vegetative development [11], stomatal conductance $[12,13]$ and xylem hydraulic conductivity [14] reduction. Likewise, drought induces mechanisms to counteract the deleterious effects of ROS [15-17], to adjust cellular homeostasis [18] and to improve the water uptake [1921]. The adjustment of plant water balance is also strongly influenced by phylloxera-resistant rootstocks [22], which exhibit a large variability in drought tolerance [23] and have a prominent role in regulation of stomatal conductance [24-26]. However, the genetic basis of drought response in rootstocks are generally poorly understood and only few works are available regarding whether rootstocks alter the gene expression of scions $[27,28]$ or whether there is an exchange of genetic material between them $[29,30]$.

Previous studies aimed to identify the genetic basis of drought response in grapevine [24, 31] and were conducted on biparental populations. Few Genome-wide association studies (GWAS) have been reported in grapevine yet, and interesting associations were found for fruit quality traits [32], leaf morphology [33] and domestication-related traits [34]. However, there are no reports to date of GWAS conducted to reveal the genetic control of drought response in grapevine. Furthermore, correct and accurate phenotyping plays a pivotal role in the dissection of genomic regions involved in drought tolerance [35]. In this regard, the application of chlorophyll fluorescence, near infrared (NIR) and hyperspectral imaging to assess grapevine phenotypes has become more common in recent years [36-39]. In the present study the application of infrared thermography allowed to evaluate rootstocks response to water deficit in an 'ad hoc' core-collection of grapes, reducing the time for phenotypic data collection, and thus allowing the screening of numerous genotypes. A GWAS approach was adopted to dissect the genomic basis of transpiration-related traits aiming to identify genetic regions involved in drought resilience potentially relevant for crop genetic improvement.

\section{Results}

\section{A genetic core collection of grape rootstocks}

The study was conducted on a genetic core collection constituted by 100 Vitis spp. accessions, listed in Table S1. A two-steps procedure was applied in order to define this restricted set of genetically highly diverse grapevine accessions as an 'ad hoc' association panel. Firstly, a core collection was created from non-vinifera Vitis species and interspecific hybrids used for fruit production, maintained at the grapevine germplasm collection of Fondazione Edmund Mach [40], to increase the allelic diversity among wild grapevines, rootstocks and hybrids accessions based on a set of 21 microsatellites. Thus, according to the M-method, 98 accessions were enough to capture the total allelic diversity (412 alleles) existing in the 231 samples analyzed. Afterwards, 41 rootstock accessions, deriving from Milano University's breeding program, and another six additional commercial rootstocks (Paulsen 1103, Kober 5BB, Selection Oppenheim 4, Millardet et de Grasset 41B, Millardet et de Grasset 101.14 and 140 Ruggeri) were included obtaining a panel of 145 individuals. In order to have an association panel easy to manage, which adequately captures as much genetic diversity as possible with a minimum of repetitiveness, it was further reduced to 100 samples based again on the M-method. At this step the six commercial rootstocks and four out of the 41 rootstocks derived from the breeding program (M1, M2, M3, M4) were arbitrary forced to be included. The number of different alleles retained by the SSRs in the final association panel was 425.

\section{Genetic diversity of the core collection}

The genetic diversity within the core collection was investigated by both SSR $(n=21)$ and SNP (GrapeReseq $20 \mathrm{~K}$ SNPs array) markers (Table 1). Regarding SNPs, after removing low quality loci, the filtered data set was made up of 16,562 SNPs. Moreover, as a consequence of the identification of missing genotypes, SNPs with a minor allele frequency (MAF) lower than 0.1 were additionally removed, remaining a final number of 7133 filtered SNPs. The average number of effective alleles was 1.51. Concerning SSR markers, 425 different alleles (A) were obtained, averaging 20.24 per locus, and allele frequencies ranged from 2.66 to 17.42 , with an average of 10.07. The values of observed $\left(\mathrm{H}_{\mathrm{O}}=0.77\right)$ and expected 
Table 1 Summary of genetic diversity parameters within the core collection and its three subpopulations

\begin{tabular}{llllllllll}
\hline & Sample & $\mathbf{N}$ & $\mathbf{A}$ & $\mathbf{A}_{\text {mean }}$ & $\mathbf{A}_{\mathbf{E}}$ & $\mathbf{H}_{\mathbf{E}}$ & $\mathbf{H}_{\mathbf{O}}$ & $\mathbf{u H}_{\mathbf{E}}$ & $\mathbf{F}$ \\
\hline SSR & Hybrids & 30 & 246 & 11.714 & 5.810 & 0.810 & 0.817 & 0.825 & -0.009 \\
& Breeding Rootstocks & 21 & 195 & 9.286 & 5.465 & 0.781 & 0.759 & 0.801 & 0.033 \\
& Roostocks/Wild & 49 & 341 & 16.238 & 8.399 & 0.839 & 0.742 & 0.849 & 0.124 \\
& Total & 100 & 425 & 20.238 & 10.065 & 0.868 & 0.768 & 0.873 & 0.116 \\
SNP & Hybrids & 30 & 14,167 & 1.986 & 1.710 & 0.396 & 0.412 & 0.403 & -0.031 \\
& Breeding Rootstocks & 21 & 13,467 & 1.888 & 1.323 & 0.201 & 0.211 & 0.208 & -0.011 \\
& Roostocks/Wild & 49 & 14,197 & 1.990 & 1.337 & 0.219 & 0.189 & 0.222 & 0.167 \\
& Total & 100 & 14,266 & 2.000 & 1.511 & 0.322 & 0.262 & 0.324 & 0.186 \\
\hline
\end{tabular}

$N$ sample size, $A$ number of different alleles, $A_{\text {mean }}$ mean number of alleles per locus, $A_{E}$ effective number of alleles, $H_{E}$ expected heterozygosity, $H_{O}$ observed heterozygosity, $u H_{E}$ unbiased expected heterozygosity, $F$ fixation index (inbreeding coefficient)

$\left(\mathrm{H}_{\mathrm{E}}=0.87\right)$ heterozygosity were almost three times higher than those estimated for SNP markers ( 0.26 and 0.32 , respectively). Lastly, the value of F index (inbreeding coefficient) was higher for SNPs (0.19) than for SSR markers (0.12).

The diversity parameters changed if Hybrids, Rootstocks/Wild and Rootstocks Breeding groups were considered separately. The number of alleles at the SSR loci varied from 195 in Rootstocks Breeding to 341 in Rootstocks/Wild, while for SNP markers it ranged from 13, 467 in Rootstocks Breeding to 14,197 in Rootstocks/ Wild. The average effective number of alleles observed among SSR loci ranged from 5.47 in Rootstocks Breeding to 8.40 in Rootstocks/Wild, whereas for SNP ones it varied from 1.32 in Rootstocks Breeding to 1.71 in Hybrids. The expected heterozygosity level estimates within groups varied from 0.78 (Rootstocks Breeding) to 0.84 (Rootstocks/Wild) for the SSRs and from 0.20 (Rootstocks Breeding) to 0.40 (Hybrids) for the SNPs. On the contrary, the subset of Rootstocks/Wild revealed the lowest values of observed heterozygosity both for SSR (0.74) and for SNP markers (0.19). Finally, the highest values of $\mathrm{F}$ index were detected in Rootstocks/Wild group both for the SSRs and SNPs $(0.12$ and 0.17 , respectively) whereas the lowest values were observed in the Hybrids subset $(-0.01$ at SSR loci and -0.03 at SNP loci).

\section{Population structure of the core collection}

The genetic structure of the analyzed population was investigated using DAPC and STRUCTURE. The DAPC analysis identified three clusters based on SSR markers (Fig. 1a). Cluster 1 included mainly rootstocks and other Vitis species (59\%) whereas Cluster 2 and Cluster 3 comprised most of the Breeding Rootstocks (81\%) and Hybrids (100\%), respectively. The model-based Bayesian clustering method in STRUCTURE software with SSR dataset (Fig. 1b) gave similar results in terms of different possible numbers of subpopulations. The $\Delta \mathrm{K}$ method [41] assigned the highest value at $K=3$, resulting in the separation of Rootstocks/Wild, Hybrids and Breeding Rootstocks in three quite distinguished groups. On the other hand, regarding the SNP dataset the same analysis showed the highest $\Delta \mathrm{K}$ value at $\mathrm{K}=2$, dividing Hybrids from other Vitis species, although a minor signal of population stratification was also found at $\mathrm{K}=4$ (Fig. 1d) and, in this case, hybrids showed a high level of genetic admixture. DAPC analysis based on SNP markers also identified four clusters (Fig. 1c): Cluster 1 and Cluster 2 mainly comprised Hybrids (40 and 60\% respectively), Cluster 3 included mostly Breeding Rootstocks (95\%) and Cluster 4 contained a large part of Rootstocks/Wild (55\%).

\section{Phenotypic characterization of the association panel under drought stress}

The evaluation of the transpiration rate under drought stress in the association population was repeatedly performed in two years, in which vines of the 100 accessions were subjected to deficit irrigation (T2-T7) or were maintained in well-watered conditions for 30 days. Water stressed vines were monitored for a week at wellwatered conditions before the imposition of water deficit (T1). Drought stress treatment resulted in a significant decrease of stomatal conductance $\left(\mathrm{I}_{\mathrm{g}}\right)$, but only in the second year experiment water-stressed plants reached transpiration values comparable with control plants after the recovery period (T8-T9) (Fig. 2). Statistically significant differences of $I_{g}$ and Crop Water Stress Index (CWSI) were observed between control (WW) and water stressed (WS) plants in both years (Table 2).

\section{Genome-wide association analysis}

The GWAS was conducted for the transpiration traits related to stomatal conductance using both GLM and MLM methods. The GLM + Q was chosen as the best model based on Quantile-Quantile plots comparisons for associations found for most of the traits under investigation. The MLM + K model was instead preferred at T4 and T9 in the first year experiment. Table 3 reports 


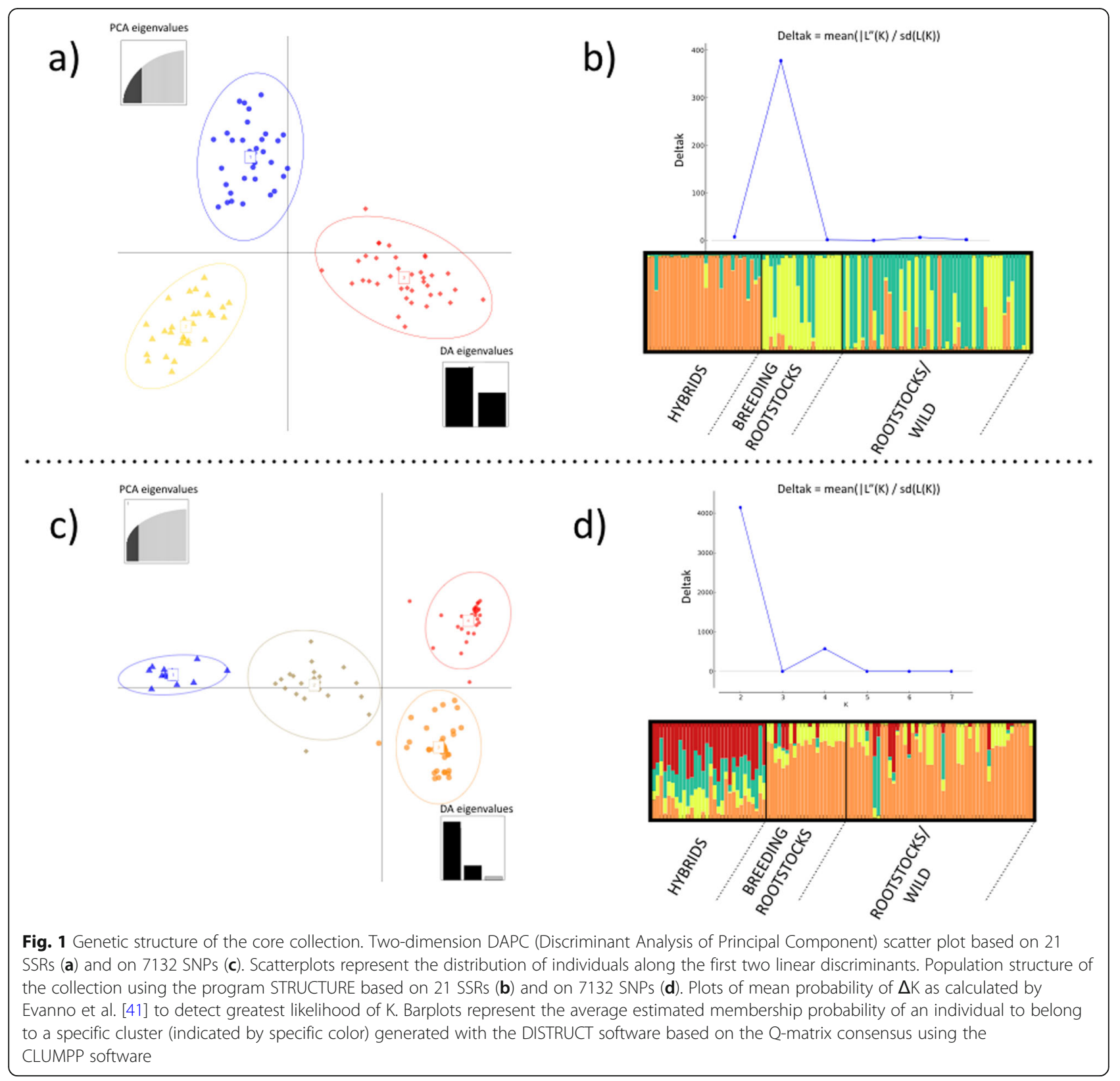

twenty-four SNPs that showed significant $p$-values after multiple testing corrections. Marker-trait significant associations were identified for stomatal conductance (Ig) values at time points $\mathrm{T} 3, \mathrm{~T} 4, \mathrm{~T} 5$ and $\mathrm{T} 9$ in water stressed plants in the first year experiment (Figure S1). Five markers out of these 24 SNPs, identified in the first year experiment, were also significant after Bonferroni correction. The SNP chr17_10,497,222_C_T showed a significant association during severe water stress (T5), two SNPs (chr13_11,950,617_C_T, chr18_13,519,938_C_T) were statistically significant under moderate water stress (T4) and two SNPs (chr3_7,009,222_A_G and chr16_21,122, 534_A_G) were significantly associated with transpiration after the recovery period (T9). Nineteen SNPs out of 24 were found significantly associated only after False Discovery Rate correction (FDR) and are, thus, identified here as suggestive associations; thirteen were detected in the first year experiment during moderate stress (T3, T4) and recovery (T9), whereas six could be found in the second year experiment at $\mathrm{T} 1$ and $\mathrm{T} 9$, that is to say, before and after (recovery) water stress, respectively. GWAS with phenotypic data collected during the second year experiment did not identify any significant association after Bonferroni correction (Figure S2). A circular Manhattan plot (Fig. 3) summarizes all the association results of both experiments.

The associated SNPs were examined to identify potential candidate genes. Firstly, it was considered 

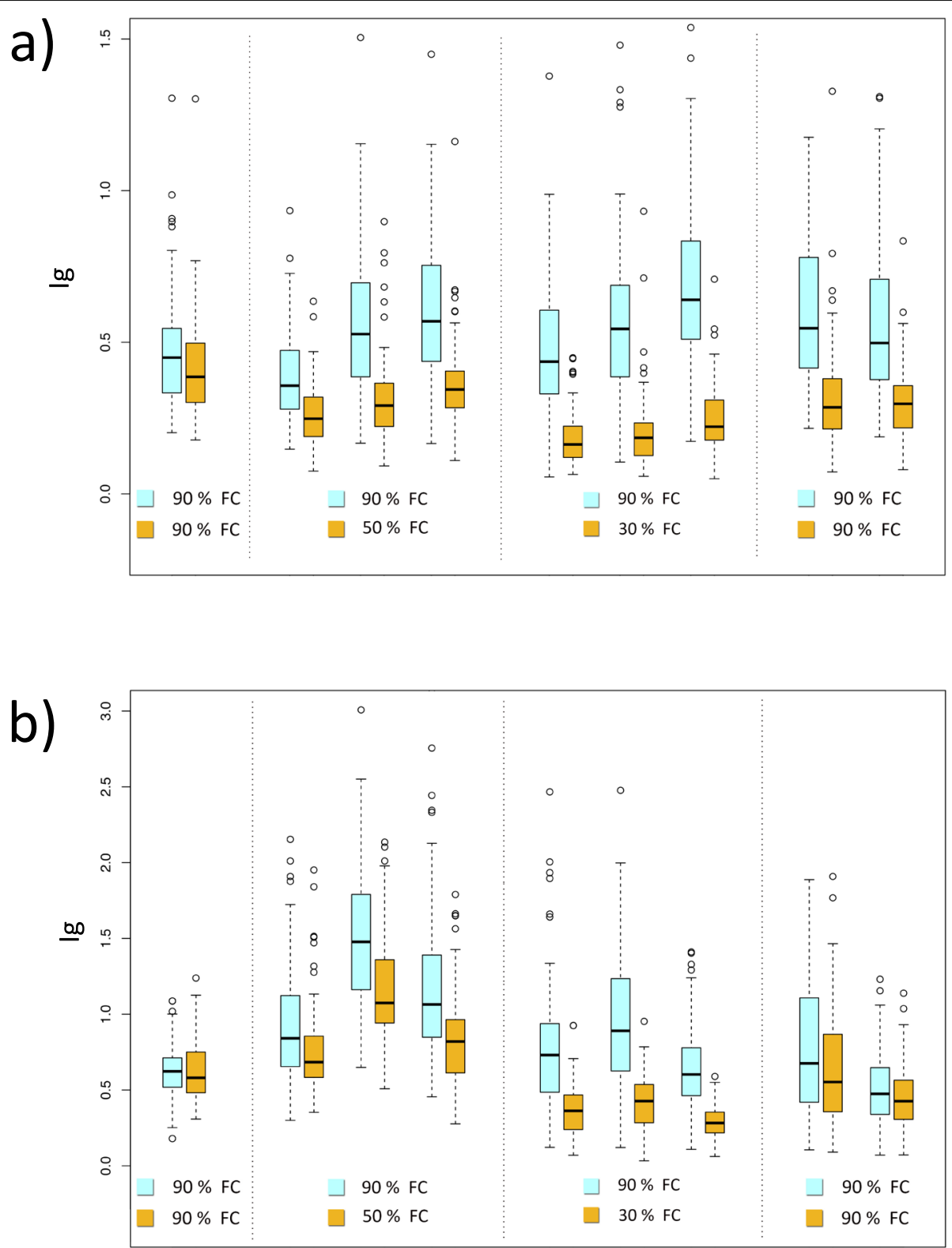

Fig. 2 Comparison of stomatal conductance indices deduced from thermal images between well-watered (WW) (in blue) and water stressed plants (WS) (in yellow) during the water stress experiments in the first year (a) and in the second year (b)

whether polymorphisms would be localized in genic regions. Out of the 24 significant SNPs (Table 3) 15 were located within genes, while the remaining SNPs were in intergenic regions. For those markers located outside gene regions or in genes functionally nonannotated, the 20 kilobases surrounding them were scanned, since Linkage Disequilibrium (LD) is reported to decay rapidly in grapevine [34, 42-44]. Thirteen candidate genes, selected according to their biological functions related to water stress response or for their position, are listed in Table 4.

\section{Validation of GWAS results}

To validate the marker-trait association found for SNPs within genes VIT_17s0000g08960, VIT_16s0098g00780, VIT_13s0106g00790 and VIT_13s0019g03040, 16 rootstock varieties were selected for a further water stress study. Transpiration rates of WW and WS plants were measured throughout the experiment with a steady state porometer. Significant differences were detected between heterozygous and homozygous plants for SNPs in the coding regions of VIT_17s0000g08960 and VIT 13s0019g03040 (Fig. 4), whereas no difference was found 
Table 2 Descriptive statistics of the phenotypic data from control (WW) and water stressed plants (WS) in each year of phenotyping

\begin{tabular}{|c|c|c|c|c|c|c|c|}
\hline \multirow[t]{2}{*}{ Year } & \multirow{2}{*}{$\begin{array}{l}\text { Time } \\
\text { points }\end{array}$} & \multirow[t]{2}{*}{ Treatment } & \multirow{2}{*}{$\begin{array}{l}\mathrm{FC} \\
(\%)\end{array}$} & \multicolumn{2}{|l|}{$\mathrm{I}_{\mathrm{g}}$} & \multicolumn{2}{|l|}{ CWSI } \\
\hline & & & & Mean & SD & Mean & SD \\
\hline \multirow[t]{18}{*}{$1^{\circ}$} & $\mathrm{T} 1$ & WW & 90 & 0.487 & 0.236 & 0.710 & 0.080 \\
\hline & & WS & 90 & 0.418 & 0.169 & 0.733 & 0.070 \\
\hline & $\mathrm{T} 2$ & WW & 90 & 0.379 & 0.140 & 0.747 & 0.066 \\
\hline & & WS & 50 & $0.264^{* * *}$ & 0.104 & $0.807 * * *$ & 0.059 \\
\hline & T3 & WW & 90 & 0.576 & 0.284 & 0.681 & 0.089 \\
\hline & & WS & 50 & $0.318^{* * *}$ & 0.153 & $0.785 * * *$ & 0.074 \\
\hline & T4 & WW & 90 & 0.623 & 0.295 & 0.655 & 0.088 \\
\hline & & WS & 50 & $0.365^{* * *}$ & 0.146 & $0.755 * * *$ & 0.067 \\
\hline & T5 & WW & 90 & 0.513 & 0.307 & 0.705 & 0.095 \\
\hline & & WS & 30 & $0.184^{* * *}$ & 0.088 & $0.859 * * *$ & 0.054 \\
\hline & T6 & WW & 90 & 0.615 & 0.357 & 0.667 & 0.117 \\
\hline & & WS & 30 & $0.205^{* * *}$ & 0.132 & $0.850 * * *$ & 0.066 \\
\hline & $\mathrm{T7}$ & WW & 90 & 0.765 & 0.467 & 0.614 & 0.111 \\
\hline & & WS & 30 & $0.247^{* * *}$ & 0.117 & $0.821 * * *$ & 0.066 \\
\hline & T8 & WW & 90 & 0.625 & 0.317 & 0.660 & 0.103 \\
\hline & & WS & 90 & $0.352 * * *$ & 0.345 & $0.779 * * *$ & 0.097 \\
\hline & T9 & WW & 90 & 0.571 & 0.282 & 0.675 & 0.093 \\
\hline & & WS & 90 & $0.325^{* * *}$ & 0.222 & $0.776 * * *$ & 0.093 \\
\hline \multirow[t]{18}{*}{$2^{\circ}$} & $\mathrm{T} 1$ & WW & 90 & 0.627 & 0.183 & 0.639 & 0.068 \\
\hline & & WS & 90 & 0.623 & 0.191 & 0.639 & 0.067 \\
\hline & $\mathrm{T} 2$ & WW & 90 & 0.926 & 0.384 & 0.566 & 0.090 \\
\hline & & WS & 50 & $0.763 * *$ & 0.300 & $0.612 * * *$ & 0.074 \\
\hline & T3 & WW & 90 & 1.540 & 0.510 & 0.443 & 0.075 \\
\hline & & WS & 50 & $1.172 * * *$ & 0.343 & $0.503 * * *$ & 0.069 \\
\hline & T4 & WW & 90 & 1.220 & 0.623 & 0.518 & 0.089 \\
\hline & & WS & 50 & $0.847^{* * *}$ & 0.309 & $0.589 * * *$ & 0.079 \\
\hline & T5 & WW & 90 & 0.798 & 0.442 & 0.615 & 0.110 \\
\hline & & WS & 30 & $0.372 * * *$ & 0.174 & $0.759 * * *$ & 0.079 \\
\hline & T6 & WW & 90 & 0.947 & 0.466 & 0.570 & 0.123 \\
\hline & & WS & 30 & $0.410^{* * *}$ & 0.185 & $0.738 * * *$ & 0.094 \\
\hline & $\mathrm{T7}$ & WW & 90 & 0.651 & 0.281 & 0.649 & 0.094 \\
\hline & & WS & 30 & $0.289 * * *$ & 0.108 & $0.795 * * *$ & 0.062 \\
\hline & T8 & WW & 90 & 0.782 & 0.438 & 0.621 & 0.125 \\
\hline & & WS & 90 & 0.659 & 0.393 & 0.653 & 0.130 \\
\hline & T9 & WW & 90 & 0.513 & 0.242 & 0.699 & 0.092 \\
\hline & & WS & 90 & 0.458 & 0.201 & 0.715 & 0.083 \\
\hline
\end{tabular}

Asterisks denote significant differences according to Mann-Whitney $U$ test between water-stressed (WS) and well-watered (WW) plants at the same time point. ${ }^{*}$, and ${ }^{* * *}$ indicate significantly different values at $p<0.01$, and $p<$ 0.001. T1: starting point where both WW and WS plants were maintained under well-watered conditions; T2-T4: WS plants were maintained at $50 \%$ of FC (moderate deficit); T5-T7: WS plants were maintained at 30\% of FC (severe deficit); T8-T9: recovery period, WS plants were rehydrated at $90 \%$ of FC in stomatal conductance for plants carrying different genetic variants in genes VIT_16s0098g00780 and VIT $13 s 0106900790$ (data not shown). As far as VIT $17 s 0000 \mathrm{~g} 08960$ is concerned, rootstocks heterozygous for this SNP exhibited a significant reduced transpiration rate compared with other varieties at the beginning of stress (T1) in WW plants and at moderate water stress (T3) in WS plants (Table S2, Fig. 4) although stomatal conductance values were lower also during severe stress (T4, T5). Regarding the mutation of VIT_13s0019g03040, significant differences between homozygous and heterozygous groups were found at moderate (T3) and at severe stress (T5) in water-stressed plants and at the beginning and end of the experiment (T1, T8) in control plants (Fig. 4, Table S2).

\section{Gene expression analysis of candidate genes under drought stress}

The expression of candidate genes VIT_17s0000g08960, VIT_18s0001g15390, VIT_16s0098g00780, VIT $13 s 0106 g 00790$ and VIT_13s0019g03040 under water stress was further investigated. Four rootstock genotypes (Richter 110, Riparia Gloire de Montpellier, 101.14 Millardet et de Grasset and SO4 Selection Oppenheim) were subjected to stress by water deprivation for 14days. These genotypes were selected both to represent putatively different classes of response to water stress and based on the SNP chr17_10,497,222_C_T at the candidate gene VIT_17s0000g08960 (Table 5).

Volumetric soil water content and stomatal conductance were determined throughout the experiment to monitor the stress evolution (Fig. 5). WS plants (water stress) showed a continuous decrease in soil water content with a substantial decline at four days from the beginning of the experiment. Interestingly, starting from 8 days after stopping irrigation, water content was significantly higher in $\mathrm{SO} 4$ compared to other genotypes. On the other hand, soil moisture in the WW control plants was maintained around 30\% during the entire experimental period. Stomatal conductance, which is considered a reference parameter of plant status in response to drought, was significantly reduced by water deficit in all the rootstocks from the fourth day. Plants exhibited different degrees of tolerance after water deprivation for two weeks. Leaves of $\mathrm{SO} 4$ remained almost green and turgid, whereas 110R and 101.14 showed some signs of plant stress and RGM vines were considerably damaged (Figure S3).

The expression of candidate genes during progressive drought stress was investigated in the leaf tissues of the four genotypes (Fig. 6). The mRNA level of VIT 17 s0000g08960 in SO4 was significantly higher after 4 days of water deprivation when plants showed first signs of stress and a notable reduction of transpiration (Fig. 5), 
Table 3 SNPs significantly associated to stomatal conductance (lg) values

\begin{tabular}{|c|c|c|c|c|c|c|c|c|}
\hline Trait & Year & SNP & $\mathrm{Chr}$ & Pos & $P$ value & QTL effect & $\mathrm{R}^{2}$ & Multiple testing corrections \\
\hline$\overline{\mathrm{Ig} T 4}$ & 1 & chr13_11,950,617_C_T & 13 & $11,950,617$ & $7.80 \mathrm{E}-06$ & $A / D$ & 0.39 & $\mathrm{BC} / \mathrm{FDR}$ \\
\hline $\mathrm{lg} T 4$ & 1 & chr18_13,519,938_C_T & 18 & $13,519,938$ & 8.30E-06 & D & 0.38 & $\mathrm{BC} / \mathrm{FDR}$ \\
\hline $\lg T 5$ & 1 & chr17_10,497,222_C_T & 17 & $10,497,222$ & 6.07E-07 & D & 0.25 & $\mathrm{BC} / \mathrm{FDR}$ \\
\hline $\mathrm{lg}$ T9 & 1 & chr3_7,009,222_A_G & 3 & $7,009,222$ & 2.34E-07 & A/D & 0.50 & $\mathrm{BC} / \mathrm{FDR}$ \\
\hline $\mathrm{I}_{\mathrm{g}} \mathrm{T} 9$ & 1 & chr16_21,122,534_A_G & 16 & $21,122,534$ & 5.24E-06 & A & 0.56 & $\mathrm{BC} / \mathrm{FDR}$ \\
\hline $\mathrm{lg} T 3$ & 1 & chr6_13,441,720_C_T & 6 & $13,441,720$ & 4.82E-05 & A & 0.22 & FDR \\
\hline $\lg T 3$ & 1 & chr11_18,012,075_T_C & 11 & $18,012,075$ & $3.28 \mathrm{E}-05$ & A & 0.22 & FDR \\
\hline $\mathrm{lg} T 3$ & 1 & chr13_10,652,062_A_G & 13 & $10,652,062$ & $3.64 \mathrm{E}-04$ & D & 0.17 & FDR \\
\hline $\lg T 3$ & 1 & chr13_4,177,522_C_T & 13 & $4,177,522$ & $2.29 \mathrm{E}-05$ & A & 0.24 & FDR \\
\hline $\lg T 3$ & 1 & chr13_1,833,944_A_G & 13 & $1,833,944$ & $1.27 \mathrm{E}-05$ & A & 0.18 & FDR \\
\hline $\mathrm{I}_{\mathrm{g}} \mathrm{T} 4$ & 1 & chr7_17,388,970_A_G & 7 & $17,388,970$ & $9.99 \mathrm{E}-06$ & $A / D$ & 0.40 & FDR \\
\hline $\lg T 4$ & 1 & chr13_11,952,742_G_T & 13 & $11,952,742$ & $1.01 \mathrm{E}-05$ & $A / D$ & 0.40 & FDR \\
\hline $\mathrm{Ig}_{\mathrm{g}} \mathrm{T} 4$ & 1 & chr5_2,431,422_C_T & 5 & $2,431,422$ & $1.24 \mathrm{E}-05$ & $A / D$ & 0.41 & FDR \\
\hline $\mathrm{lg} T 4$ & 1 & chr4_18,754,964_C_T & 4 & $18,754,964$ & $1.60 \mathrm{E}-05$ & $A / D$ & 0.37 & FDR \\
\hline $\mathrm{Ig}_{\mathrm{g}} \mathrm{T} 4$ & 1 & chr3_235,211_C_T & 3 & 235,211 & $1.60 \mathrm{E}-05$ & $A / D$ & 0.36 & FDR \\
\hline $\mathrm{Ig}_{\mathrm{g}} \mathrm{T} 4$ & 1 & chr13_2,031,649_T_C & 13 & $2,031,649$ & $1.73 \mathrm{E}-05$ & $A / D$ & 0.36 & FDR \\
\hline $\lg$ T9 & 1 & chr10_1,989,600_G_T & 10 & $1,989,600$ & 4.71E-05 & $A / D$ & 0.42 & FDR \\
\hline Ig T9 & 1 & chr13_2,751,641_A_C & 13 & $2,751,641$ & 5.51E-05 & $\mathrm{A} / \mathrm{D}$ & 0.40 & FDR \\
\hline $\lg T 1$ & 2 & chr14_3,096,968_G_T & 14 & $3,096,968$ & $9.96 \mathrm{E}-06$ & A & 0.25 & FDR \\
\hline $\lg T 1$ & 2 & Chr13_4,177,522_C_T & 13 & $4,177,522$ & 4.98E-05 & A & 0.22 & FDR \\
\hline $\mathrm{lg}$ T9 & 2 & chr7_17,388,970_A_G & 7 & $17,388,970$ & $3.78 \mathrm{E}-05$ & $A / D$ & 0.23 & FDR \\
\hline $\lg$ T9 & 2 & chr7_20,777,757_C_T & 7 & $20,777,757$ & 4.36E-05 & D & 0.27 & FDR \\
\hline $\mathrm{Ig}_{\mathrm{g}} \mathrm{T} 9$ & 2 & chr9_553,031_C_T & 9 & 553,031 & $2.04 \mathrm{E}-05$ & $A / D$ & 0.27 & FDR \\
\hline $\mathrm{I}_{\mathrm{g}} \mathrm{T} 9$ & 2 & chr13_11,950,617_C_T & 13 & $11,950,617$ & $6.57 \mathrm{E}-05$ & $A / D$ & 0.23 & FDR \\
\hline
\end{tabular}

SNPs significantly associated according to the Bonferroni Correction $(B C)$ and False Discovery Rate (FDR). $R^{2}$ : the proportion of phenotypic variance explained by the marker. Positions are referred to V1 annotation of the Vitis vinifera genome (http://www.genoscope. cns.fr)

whereas its expression decreased in the later stages of the experiment. On the other hand, the relative expression of VIT_ 17 s0000g08960 did not vary in response to drought in RGM, 110R and 101.14. Regarding VIT_18s0001g15390 its transcript level was increased by water deficit, even if the peak of expression was after 6 days in RGM and 101.14 and after 11 days in 110R and SO4. A comparable time-course profile was observed for the VIT_13s0019g03040 mRNA that was significantly modulated in the four genotypes. VIT_13s0106g00790 was up-regulated only in RGM plants, with higher level of expression at 6 days. Finally, the relative expression of VIT_16s0098g00780 remained basically unchanged during the experiment.

\section{Resequencing of candidate gene VIT_17s0000g08960 in the association population}

In order to detect a potential causative variant, the coding region of VIT_17s0000g08960 was sequenced in 85 individuals of the core collection (Table S1). A summary of the key genetic diversity parameters observed through analysis of $2343 \mathrm{bp}$ of the coding sequence is shown in Table 6.

VIT_17s0000g08960 contains 4 exons as reported in the gene annotation deposited on Grape Genome Database v2.1. Resequencing allowed identification of 134 SNPs, revealing a frequency of polymorphic sites equal to one SNP every $17 \mathrm{bp}$. Only one INDEL was found in exonic regions. The nucleotide diversity $(\pi=0,007)$ and the number of segregating sites $(\theta=0,011)$ provided an estimate of the genetic variation at the nucleotide level. Synonymous sites, on the other hand, showed a nucleotide diversity value $(0.015)$ much higher than nonsynonymous sites (0.005). In addition, genetic variation level estimated by dividing Vitis accessions into two subsets (Rootstocks and Hybrids) is reported in Table S3. The Rootstocks subset exhibited greater rate of polymorphisms (one SNP every $21 \mathrm{bp}$ ) and lower nucleotide diversity $(\pi=0,006, \theta=0,011)$ than the Hybrids subgroup (one every $33 \mathrm{bp}, \pi=0,007, \theta=0,007$ ). Neutrality tests were estimated using two values, Tajima's $\mathrm{D}$ value and $\mathrm{Fu}$ and Li's $\mathrm{F}$ value. Both tests indicated that the 


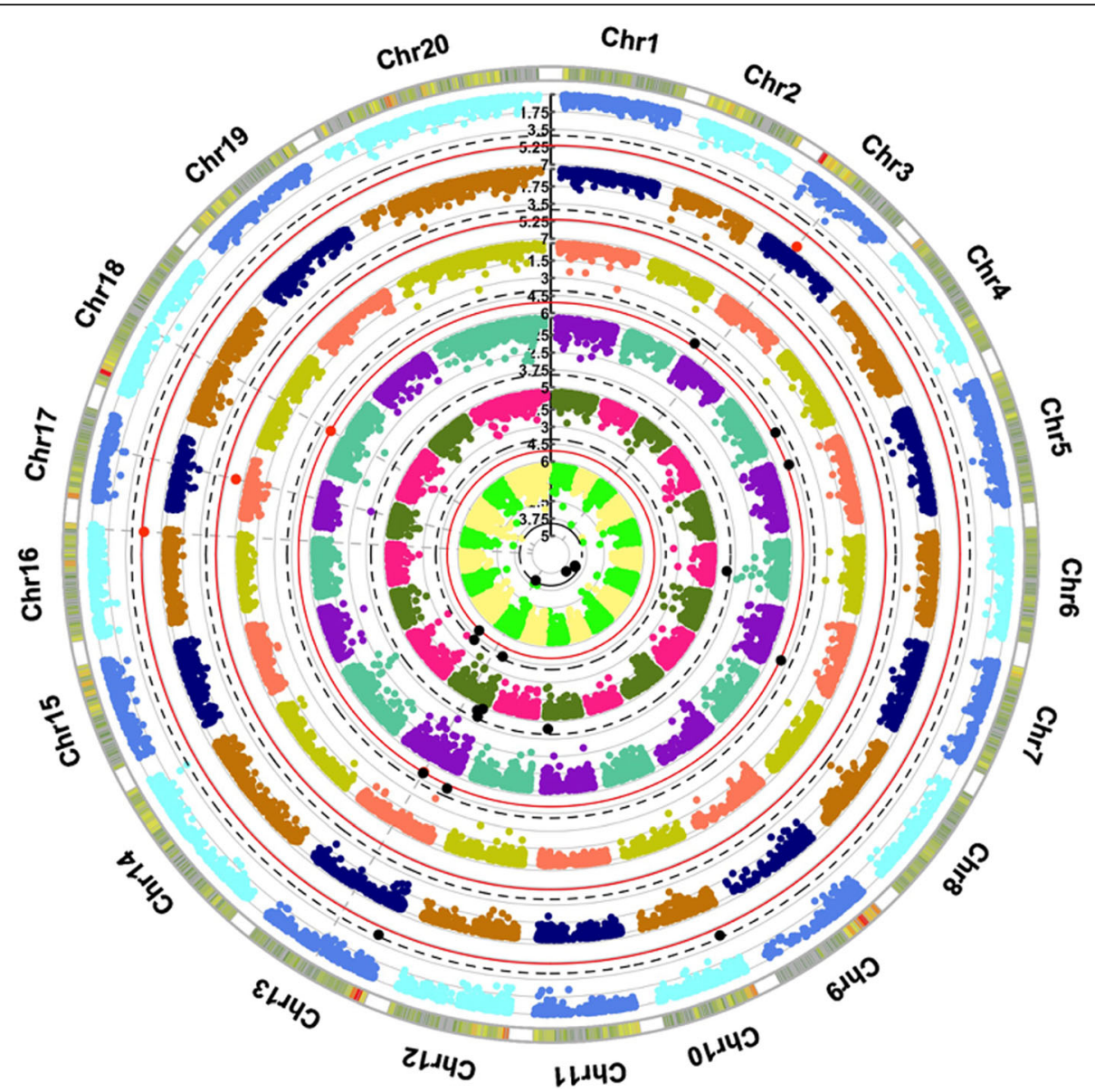

Fig. 3 Circular Manhattan plot of association analysis between stomatal conductance (lg) values and all SNP sites at time points T3 (aquamarin, violet), T4 (dark yellow, salmon), T5 (blue, orange), and T9 (azure, light blue) of first year experiment and time points T1 (dark green, pink) and T9 (green, yellow) of second year experiment. The red and black dots indicate respectively significant values according to the Bonferroni-corrected p-value and False Discovery Rate (FDR)

Table 4 List of candidate genes functionally annotated

\begin{tabular}{|c|c|c|c|c|c|c|}
\hline Trait & Year & Candidate gene & Description & Chr & Start & Stop \\
\hline $\mathrm{Ig} T 4$ & 1 & VIT_18s0001g15390 & Peroxidase & 18 & $13,521,135$ & $13,522,636$ \\
\hline $\lg T 5$ & 1 & VIT_17s0000g08960 & Raffinose synthase & 17 & $10,494,444$ & $10,498,141$ \\
\hline $\mathrm{Ig}_{\mathrm{g}} \mathrm{T9}$ & 1 & VIT_03s0091g00570 & Transcription factor & 3 & $6,998,808$ & $6,999,512$ \\
\hline $\mathrm{I}_{\mathrm{g}} \mathrm{T} 9$ & 1 & VIT_16s0098g00780 & laa-amino acid hydrolase & 16 & $21,120,452$ & $21,126,524$ \\
\hline $\mathrm{Ig}_{\mathrm{g}} \mathrm{T9}$ & 1 & VIT_16s0098g00760 & Transcription factor & 16 & $21,111,871$ & $21,115,426$ \\
\hline $\lg T 3$ & 1 & VIT_06s0009g01570 & Serrate rna effector molecule & 6 & $13,438,002$ & $13,465,222$ \\
\hline $\mathrm{Ig}_{\mathrm{g}} \mathrm{T3}$ & 1 & VIT_11s0052g00570 & Auxin-induced protein 5NG4-like & 11 & $18,007,469$ & $18,008,509$ \\
\hline $\mathrm{Ig} T 3$ & 1 & VIT_13s0106g00790 & Mevalonate diphosphate decarboxylase & 13 & $10,642,954$ & $10,652,636$ \\
\hline $\lg T 3$ & 1 & VIT_13s0019g03040 & Glycosyltransferase & 13 & $4,177,111$ & $4,179,273$ \\
\hline $\mathrm{Ig}_{\mathrm{g}} \mathrm{T} 4$ & 1 & VIT_05s0020g00540 & $\beta$-xylosidase/a -arabinofuranosidase & 5 & $2,435,691$ & $2,438,632$ \\
\hline $\mathrm{I}_{\mathrm{g}} \mathrm{T} 9$ & 1 & VIT_10s0003g00760 & Glutamate receptor protein & 10 & $1,992,263$ & $1,998,191$ \\
\hline $\mathrm{lg} T 1$ & 2 & VIT_14s0128g00480 & Eukaryotic translation initiation factor 3 subunit J & 14 & $3,092,047$ & $3,097,166$ \\
\hline $\mathrm{Ig}_{\mathrm{g}} \mathrm{T9}$ & 2 & VIT_09s0002g00810 & Peroxisomal (S)-2-hydroxy-acid oxidase GLO4 & 9 & 547,420 & 552,404 \\
\hline
\end{tabular}

Positions are referred to V1 annotation of the Vitis vinifera genome (http://www.genoscope. cns.fr) 

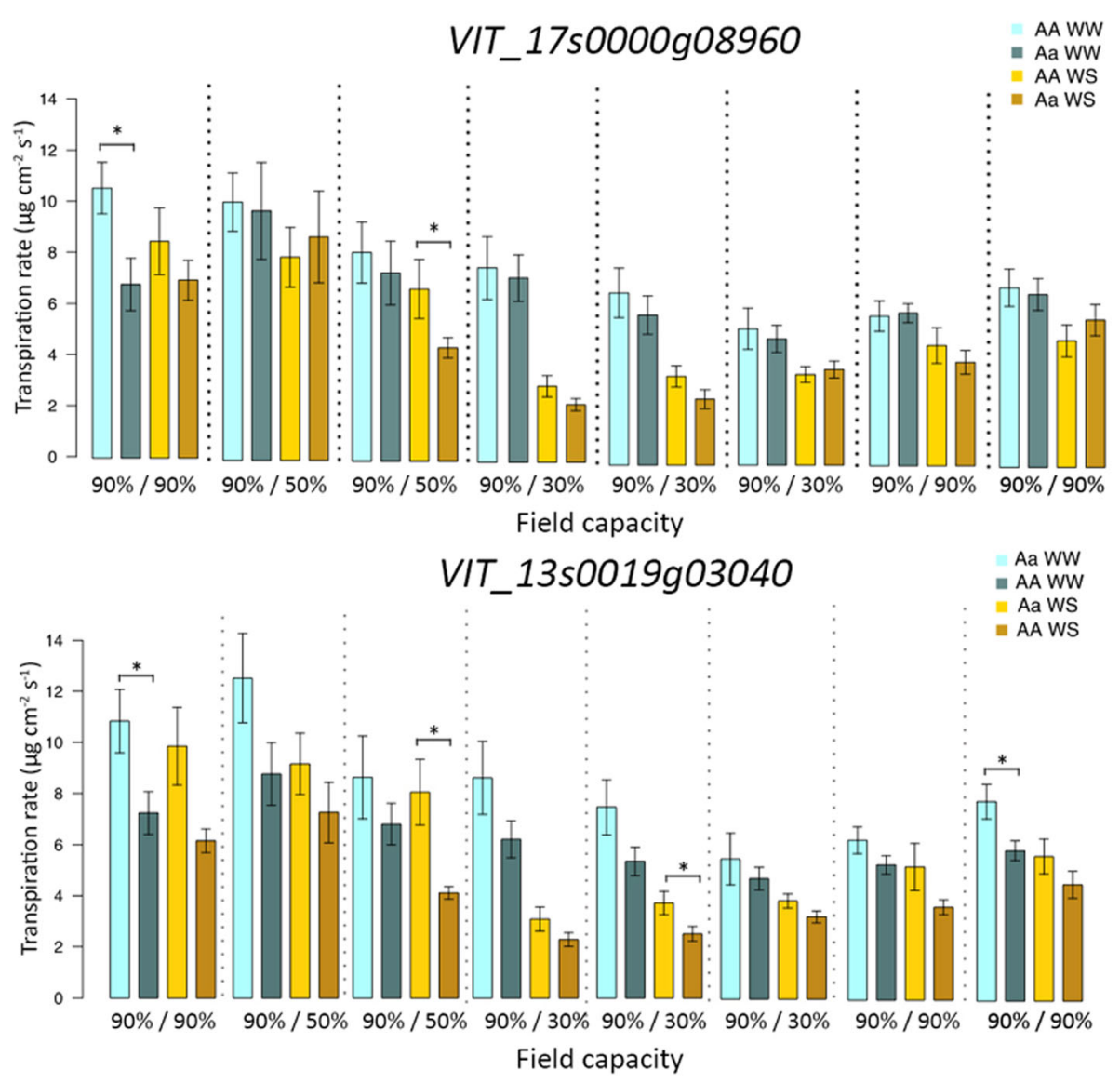

Fig. 4 Comparison of transpiration rate between well-watered (WW) (in blue) and water stressed plants (WS) (in yellow) during the water stress experiment in the third year. Plants were divided for SNPs in the coding regions of VIT_17s0000g08960 and VIT_13s0019g03040. Asterisks denote significant differences according to Mann-Whitney $U$ test between plants on the same time point and under the same treatment at $p<0.05$

polymorphisms did not show any significant deviation from neutrality neither in the whole dataset nor in the subsets of Rootstocks and Hybrids. The impact of nonsynonymous substitutions on the biological function of the protein was predicted for all 69 mutations detected. Seventeen showed a PROVEAN score below - 2.5, which indicates a probable structural alteration of protein (Table S4). Additionally, some of these deleterious mutations occur in a significant proportion of the rootstock population.

\section{Discussion}

The genetic core collection of grape rootstocks

The existing grape germplasms are valuable genetic resources that could be examined for seeking phenotypic variations in drought tolerance mechanisms. Constructing a genetic core collection has proved to be an adequate strategy to obtain an optimal number of rootstock genotypes which captures all the most frequent alleles of a large germplasm, which is in agreement with previous studies [40, 42, 45]. Moreover, the

Table 5 Rootstocks classification based on response to drought

\begin{tabular}{lll}
\hline Genotype & WS response class [22] & $\begin{array}{l}\text { SNP chr17_10,497,222_C_T } \\
\text { (CT overdominance effect) }\end{array}$ \\
\hline SO4 (V. riparia $\times$ V. berlandieri) & sensitive (1) / resistant (2) & $C T$ \\
101.14 (V. riparia $\times$ V. rupestris) & sensitive $(1,2)$ & $\Pi$ \\
$110 R(V$. rupestris $\times$ V. berlandieri) & highly resistant $(1,2)$ & $\Pi$ \\
Riparia Glorie de Montpellier $(V$. riparia) & very sensitive $(1,2)$ & $C C$ \\
\hline
\end{tabular}




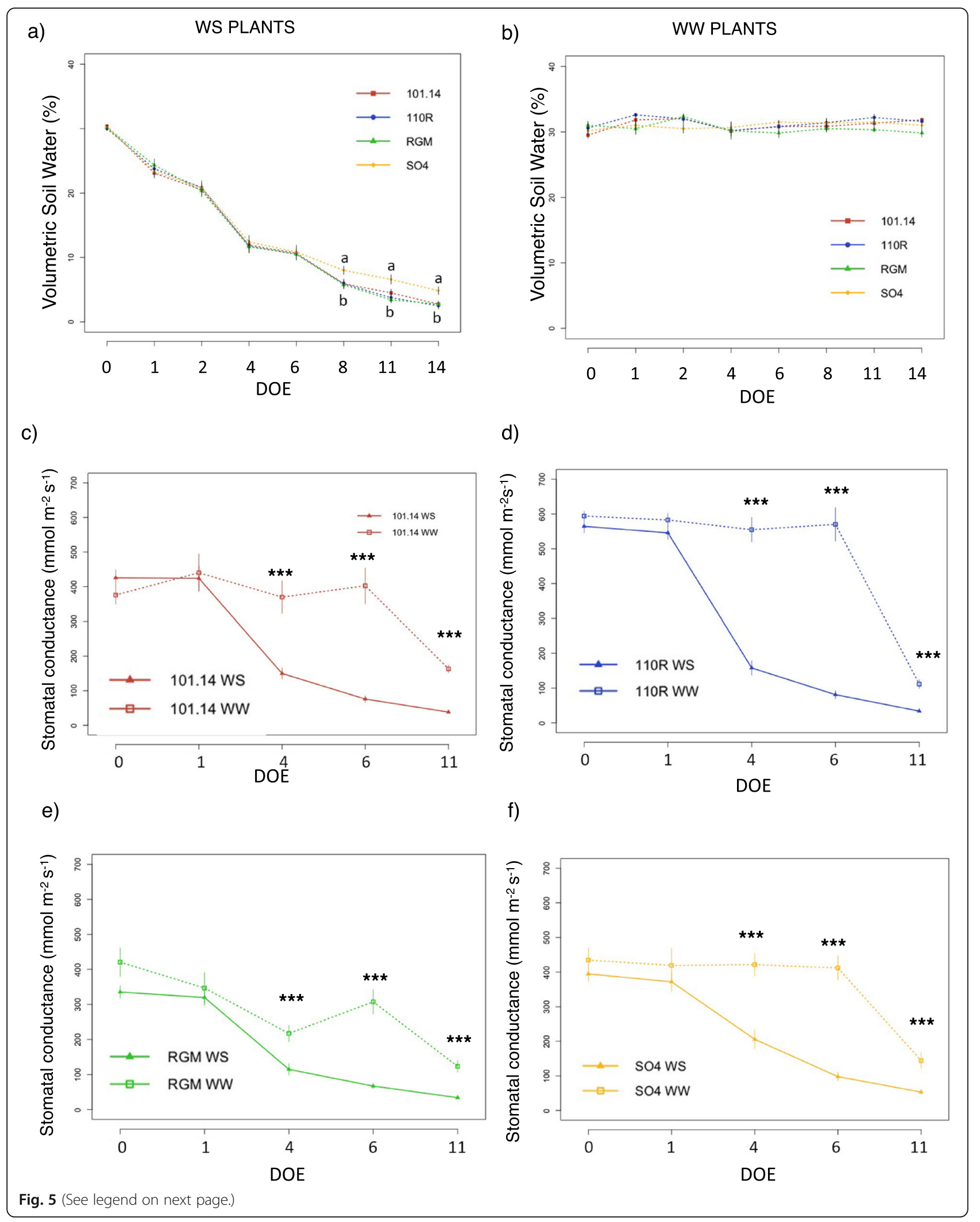


(See figure on previous page.)

Fig. 5 Physiological conditions of rootstocks during water stress experiment. Volumetric soil water content evaluated throughout the progression of the drought stress experiment of water stress group (a) and of control group (b). Values represent average measurements \pm SE of twelve replicates (WS) and six replicates (WW). Data were analysed using one-way ANOVA with LSD post-hoc test, and letters indicate significant differences between genotypes on the same day at $p<0.05$. Stomatal conductance of water stressed (WS) and well watered (WW) 101.14Mgt (c), $110 \mathrm{R}(\mathbf{d}), \mathrm{RGM}(\mathbf{e})$ and SO4 (f) throughout the experiment. Values represent average measurements $\pm \mathrm{SE}, n=12$ (WW) and $n=24$ (WS). Significant differences between treatments on the same day were tested with Mann-Whitney $U$ test, and asterisks indicate significantly different values at $p \leq 0.05\left(^{*}\right), p \leq 0.01\left(^{* *}\right)$, and $p \leq 0.001\left(^{* *}\right)$. DOE, days of experiment

use of a genetic core collection for marker-trait association studies was applied in several plant species with excellent results [42, 46-48]. Our results showed that a relatively few accessions were required to represent the whole genetic diversity with the minimum redundancy, probably due to the high heterozygosity of Vitis species [49]. Similar outcomes have been reported in Malus [50], which exhibits high levels of heterozygosity as well, whereas more individuals were needed in M. truncatula [51] that is characterized by lower allelic heterozygosity.

A considerable level of genetic diversity within the core collection has been confirmed by the analysis with microsatellites and SNP markers and both proved to be highly informative. Conversely, the level of heterozygosity estimated by SNPs was substantially lower compared to that obtained with SSRs, as expected, since markers of bi-allelic nature have a lower discrimination power and detect a smaller proportion of rare alleles in a population [52, 53]. The slight reduction of Ho in comparison with $\mathrm{H}_{E}$ may be the result of inbreeding events on the population under investigation, as noted in previous studies $[40,54,55]$, and the low $\mathrm{F}$ values are also attributable to the high heterozygosity of grapevine. Furthermore, an overall reduction of genetic diversity has been observed within the Breeding Rootstocks pool compared to the Rootstocks/Wild and Hybrids panels, because they were obtained through a breeding selection based on few progenitors.

Regarding the genetic structure of the core collection, Hybrids were grouped clearly in a distinct cluster separated from Breeding Rootstocks and Rootstocks/Wild. This outcome was predictable because hybrids were obtained by crossing American Vitis species with cultivated grapevines carrying both phylloxera resistance and a significant percentage of $V$. vinifera in their pedigree [56].

\section{Phenotyping of drought stress response}

Grapevine WUE under droughts is strongly influenced by plant transpiration rate, which can be, therefore, considered a potential target for its improvement [57]. Thermal infrared imaging was confirmed as a very suitable tool for the estimation of stomatal conductance and to study the genotypic variability related to transpiration. During the three experimental years, rootstocks exhibited significantly higher canopy temperatures in comparison with their controls when subjected to water stress, reflecting their water status. Moreover, it was demonstrated that Ig and CWSI parameters, deduced from thermal images, were significantly correlated with water stress indicators, such as leaf water potential $(\Psi \mathrm{L})$, non-photochemical quenching (NPQ) or efficiency of light use by the photosystem II (PSII) [58]. The timing of measurements is critical to ensure satisfying phenotyping results and this approach allowed a fast assessment of the transpiration rate in the whole rootstock population (600 vines) in the same day and during a specific time window to limit environmental influence, which would have been impossible with a porometer. In fact, since the initial development of the thermography method by Blum et al. [59], water status of different kind of crops has been widely studied with excellent results in diverse research works, including grapevine $[38,39,60-$ 62]. This experiment demonstrated the effectiveness of thermal imaging in detecting genome wide-associations overall. Moreover, the analysis of drought response on a subset of the population using direct stomatal conductance measurements proved the consistency of these outcomes. Nevertheless, it is essential to investigate other morphological characteristics, such as vegetative development or root architecture, and evaluate physiological aspects of rootstock-scion interaction in both pot and field experiments, in order to acquire a full knowledge of the plant physiological response.

\section{Genome-wide association analysis}

GWAS studies are currently a valuable approach to understand the genetic basis of complex traits [63], particularly for those with polygenic inheritance, such as drought tolerance, although these analyses are not widely carried out in grapevine [32-34, 64-66]. According to Nicolas et al. [43] the ideal association panel for GWAS in grapevine should combine limited relatedness with minimal structure. The panel designed for this study was composed by hybrids, wild non-vinifera accessions and rootstock varieties (Table S1) that included in their pedigree the main American Vitis species, such as $V$. riparia, $V$. berlandieri and $V$. rupestris. Therefore, it ensures a large genetic variability and, additionally, exhibits unexplored variations for biotic and abiotic 


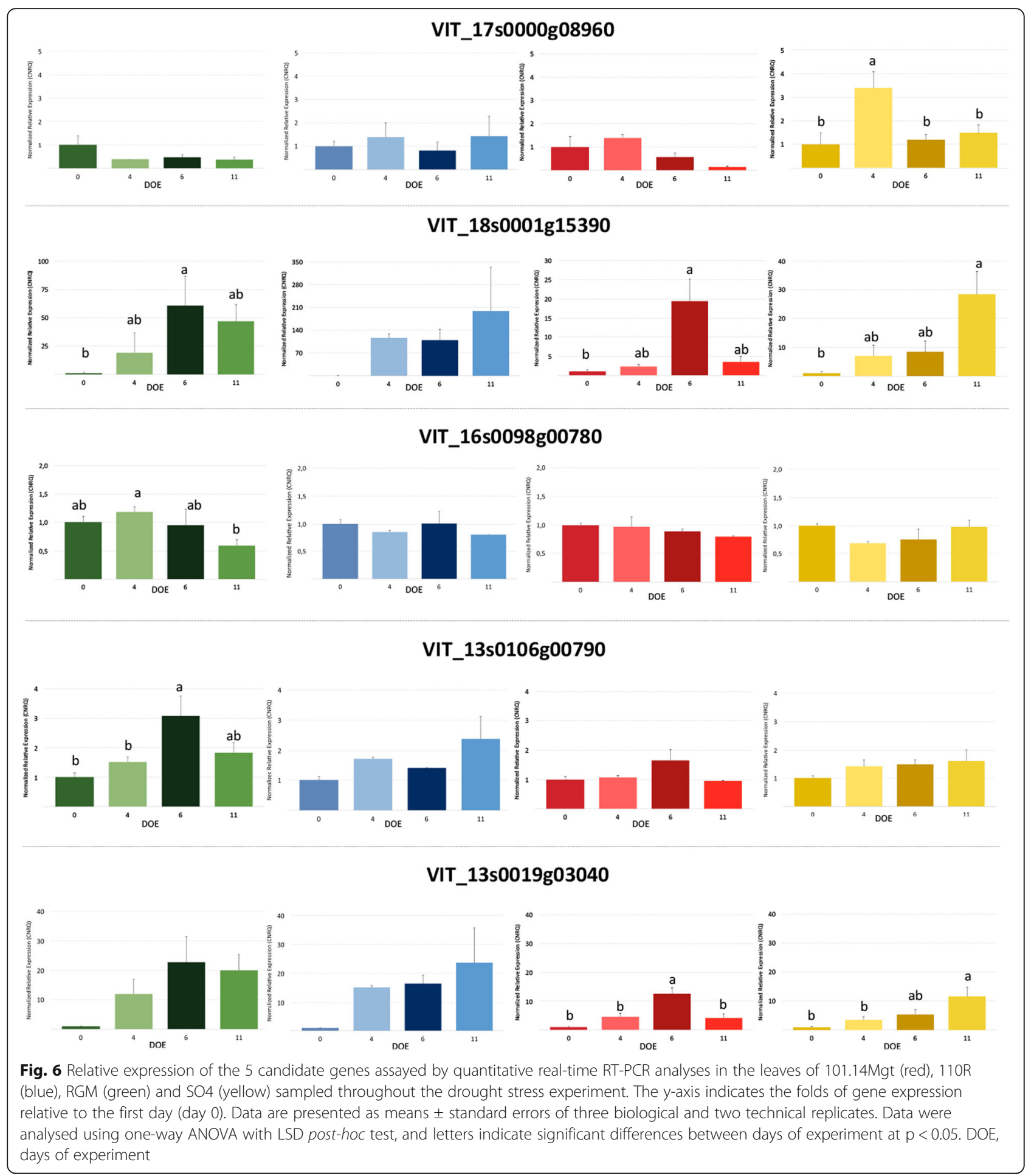

stresses resilience [67, 68]. However, GWAS analysis identified only five SNPs which passed the Bonferroni significance threshold associated with the studied phenotypic traits. On the other hand, nineteen marker-trait associations were detected using FDR's less conservative approach. The decrease of statistical power could be caused by the rapid decay of LD in grape [43, 66, 69] that might require a large number of SNPs to evenly cover the genomic region. The GrapeReseq $20 \mathrm{~K}$ SNPs array proved to be an adequate tool to detect significant genotype-phenotype associations in this study. This chip includes probes targeting variations discovered within 47 wild and cultivated genotypes of $V$. vinifera, but also 4978 SNPs identified in 18 accessions of other six Vitis 
Table 6 Summary statistics of VIT_17s0000g08960 protein coding region sequencing in the grape rootstocks population

\begin{tabular}{llll}
\hline Parameters & N & Synonymous changes & Non-synonymous changes \\
\hline Vitis accessions & 85 & & \\
Full-ORF cDNA & $2343 \mathrm{bp}$ & & \\
Predicted protein & $780 \mathrm{aa}$ & & 69 \\
Exons & 4 & 65 & 0,005 \\
Introns & 3 & & \\
Number of polymorphic sites & 135 & 0,015 & \\
SNPs & 134 & & \\
INDELS & 1 & & \\
Nucleotide diversity $(\pi)$ & 0,007 & 0,011 & \\
Watterson's estimator $(\theta)$ & &
\end{tabular}

species. Therefore, it was appropriate for genotyping the core collection, which contains several different Vitis genotypes. Moreover, the SNP markers on array were selected based on their level of heterozygosity and evenly distributed along chromosomes. This array, in fact, has allowed detection of QTLs for vegetative and reproductive traits [Houel et al. 2015] and a great estimation of genetic diversity in grapevine germplasms [33, 53, 64]. On the other hand, a greater number of SNP markers could have been obtained through either the Restrictionsite associated DNA sequencing (RADSeq) or the Genotyping by Sequencing (GBS) approach. Maximizing the number of SNPs may indeed increase the likelihood of finding significant associations with the phenotype. However, this strategy requires a more accurate filtering of the SNPs discovered and needs to be previously optimized for the different genotypes under investigation. In the present study the plants under investigation are either hybrids or accessions from different Vitis species and it is possible that they may differ in terms of the presence of restriction enzymes sites in highly repetitive DNA regions. Furthermore, drought tolerance is a trait with a complex polygenic determinism and with a strong environmental interaction and, hence, a marker-trait association analysis will probably require highly precise phenotypic data, and an experimental panel including more individuals and replicates, in order to detect minor effect QTLs.

The prominent role of rootstocks in regulating scion stomatal conductance under water deficit has been demonstrated in different studies [25, 26, 70, 71], although the genetic determinism involved in the stomatal regulation has been scarcely investigated. Marguerit et al. [24] identified, through a QTL analysis, genetic regions in rootstocks linked to the transpiration control of scions by evaluating drought response of a single scion genotype grafted on 138 individuals from a $V$. vinifera cv.
Cabernet Sauvignon $\times V$. riparia $\mathrm{cv}$. Gloire cross. Later, Coupel-Ledru et al. [31] dissected the genetic basis of stomatal sensitivity between iso- and aniso-hydric grapevines in a progeny (Vitis vinifera L. cvs. Grenache $\times$ Syrah) again with a QTL approach. So far, these remain the only studies focused on identifying the genetic regions responsible for stomatal control under water stress.

The association mapping approach adopted in this study detected significant genotype- phenotype associations during the various stages of drought stress of the experiment. GWAS results of the second year, however, were not consistent with those obtained during the first year. This fact highlights the need to cope with challenges of plant phenotyping for drought tolerance, which may be influenced by multiple abiotic stress conditions, such as excessive heat $[35,72]$. Indeed, despite the experiments were conducted in a tunnel- greenhouse, external conditions were slightly different likely having an impact on inside temperature. Differences were also noticed regarding the transpiration response. Environmental conditions reduced the stomatal conductance of control plants in the first year and water-stressed plants exhibited a transpiration rate close to zero at $30 \%$ of FC, showing only a partial recovering after rehydration. Nevertheless, phenotypic data collected in a third year on a subset of the population with a porometer, which measures more accurately the stomatal conductance, confirmed some of the associations.

Previous genetic studies of the grapevine transpiration under drought [24, 31] reported a comprehensive characterization of the population over the course of the water treatment, even though the low density of markers limited the resolution of QTL confidence intervals, which included large chromosomic regions. However, the large amount of significantly associated SNPs identified in this study co-localized in those QTL regions, 
even indicating more restricted positions. Therefore, the application of an integrated strategy combining QTL mapping and GWAS analysis seems a valid approach to dissect complex traits, such as drought stress response.

\section{Potential candidate genes for drought tolerance}

The significantly associated SNP chr17_10,497,222_C_T $(p<0.0001)$ was identified under severe water deficit conditions in the first year experiment. Moreover, other association signals for the same marker, which did not exhibit significant $p$-values after multiple testing corrections, were found in the first year (at 50\% of FC) and in the second year (at recovery stage). Additionally, the association of the SNP with a different rate of transpiration under drought was validated in a small group of rootstock varieties in a third year experiment. Indeed, genotypes with heterozygous SNP (CT) exhibited a significant reduction of stomatal conductance compared with genotypes carrying homozygous SNP (CC or TT) at $50 \%$ of FC. The SNP chr17_10,497,222_C_T is located in the coding region of VIT_17s0000g08960, which codes for a raffinose synthase. The raffinose family of oligosaccharides (RFOs) has a fundamental role in protecting plants against abiotic stresses [73]. These proteins confer tolerance against drought stress acting as signaling compounds through the phloem, and as storage of additional energy resources. In addition, they have a ROS scavenging function and stabilize cellular membranes and photosynthetic apparatus. The accumulation of these carbohydrates also improved the water stress tolerance in several plants, such as Arabidopsis thaliana [74-76], Medicago sativa [77], Xerophyta viscosa [78], Zea mays [79], Coffea [80] and Malus domestica [81]. Grapevines subjected to drought generally show an overall reduction of sugars [82], probably due to a decreased carbon fixation, except for galactinol and raffinose, which accumulate upon water deficit conditions [17], suggesting, therefore, that their biosynthesis is strictly related to stress. Furthermore, the concentration of osmolytes like raffinose in guard cells has a role in the regulation of stomata aperture $[83,84]$. The involvement of VIT 17 s0000g08960 in drought response mechanisms, including ABA-mediated signalling, is confirmed by transcriptomic studies in grapevine. It was differentially modulated in leaves of isohydric and anisohydric varieties under water deficit conditions [85] and it was up regulated in Merlot grapevine leaves subjected to drought [17], in transgenic grape cells overexpressing $V v A B F 2$ [86] and in berries after ABA treatment [87]. Phylogenetic analysis of the protein codified by VIT $1750000 g 08960$ has also demonstrated that it is closely related to stress-inducible protein raffinose synthase 5 (RS5) of Arabidopsis, that has proved to be the solely responsible for raffinose accumulation in leaves under water stress [88]. The role of VIT_17s0000g08960 in drought stress response was also supported by the in silico analysis of its promoter, which exhibited a consistent enrichment for major ABA-responsive elements (ABRE) and dehydration-responsive element binding (DREB) motifs (ACGTG, RYACGTGGYR, YACGTGGC, ACGTGKC, ACCGAC) [89-93]. Accordingly, the VIT 17s0000g08960 coding region has been sequenced in 85 rootstock genotypes in order to detect a potential causative variant. Its nucleotide diversity $(\pi=0,007)$ is higher than the average values observed in grapevine gene regions reported in literature $(\pi=0,0040-0,0051)$ [42, 94 96], which is consistent to the complex nature of the highly diverse association panel that includes different Vitis species and hybrids and thereby presenting a large genetic variability. Interspecific hybrids, which all include $V$. vinifera in their pedigrees, showed a lower frequency of polymorphic sites compared with other rootstock genotypes. On the other hand, if mutations in the non-coding portions of the genome are considered, the genetic diversity in grapevine is substantially higher both in wild and cultivated varieties ranging from $\pi=0$, 015 and $\pi=0,014$, respectively [97]. Despite a recently published whole-genome resequencing of 472 Vitis accessions revised downwards these estimates, nucleotide diversity values of $\pi=0,0035$ for wild and $\pi=0,0055$ for domesticated cultivars were reported [49]. Unfortunately, none of the non-synonymous changes of VIT 17 s0000g08960 coding region proved to be in LD with the associated variant identified in GWAS. Thus, the putative causative mutation in LD with the significant synonymous SNP could be located in genomic regions that have not been sequenced; cis-regulatory sequences can be localized in intragenic (introns) or intergenic (promoter and enhancer) regions closely surrounding the gene and need to be further investigated.

In the GWAS experiment SNP chr17_10,497,222_C_T was significantly associated with stomatal closure in drought stress conditions with an overdominance effect, heterozygous (CT) genotypes showed lower stomatal conductance in comparison with homozygous genotypes (CC or TT). In this respect, commercial rootstocks (representative of the three genotypic classes) were deeply characterized under drought in a pot stress experiment. Interestingly, as soil water content decreased $\mathrm{SO} 4$ vines proved to be the more able to preserve soil moisture. In accordance with our results, Tramontini et al. [25] reported that different grapevine genotypes grafted on $\mathrm{SO} 4$, grown under water-limiting conditions in small pots, preserved the soil water in a more efficient way compared with the same varieties grafted on high tolerant rootstock, 140 Ruggeri. The analysis of the VIT $17 s 0000 g 08960$ transcripts during water deficit revealed that this gene was modulated only in $\mathrm{SO} 4$ vines. A 
significantly higher expression was detected after four days, when plants start to perceive the symptoms of stress, indicating that it might be implicated in early response to drought stress. Therefore, the potential causative mutation could have a role in the transcriptional regulation.

Among the other significantly associated markers, SNP chr18_13,519,938_C_T is positioned within the promoter region of another drought responsive gene, VIT 18s0001g15390, which encodes a peroxidase protein. Peroxidases are antioxidant enzymes that prevent excessive damages caused by ROS accumulation and their concentrations are highly modulated under abiotic stresses [98, 99]. Moreover, its expression profile during drought was characterized by a progressive increase of transcripts throughout the experiment in all the four rootstocks genotypes, which supports a prominent role in the stress response. The other three statistically significant polymorphisms after Bonferroni adjustment, chr3_7,009,222_A_G, chr16_21,122,534_A_G and chr13_11,950,617_C_T, map near a TF involved in transcription initiation, in the intronic region of an iaaamino acid hydrolase and in a non-annotated gene prediction, respectively. Since these genes could not be considered directly related to water stress response, surrounding genomic regions were scanned without finding credible candidate genes. However, these regions would deserve much more in-depth analysis because candidate gene approach could be limiting and may exclude non-coding regions actually associated with the phenotype (promoters, enhancers, silencers, etc.) [100]. The Bonferroni correction test is the most applied for assessing the threshold value of associations. Nonetheless, it is often too conservative and some signals may not pass its stringent criteria. Thus, SNPs suggested based on FDR were also considered to detect other marker-trait association. All the identified markers were found only during one stage of stress, except chr13_4, 177,522_C_T. This SNP, located in the coding region of a glucosyltransferase protein (VIT_13s0019g03040), was found significant under both moderate water deficit and well-watered condition. Several recent studies in model plant species also suggest the involvement of glycosyltransferases in abiotic stress adaptation [101-103]. Furthermore, we observed that VIT_13s0019g03040 expression increases along drought experiment in the studied rootstock varieties, so it might play a key role in drought response mechanisms. Lastly, marker chr13_10, 652,062_A_G was found associated in plants under moderate drought stress and it is positioned in the coding region of mevalonate diphosphate decarboxylase (MVD) (VIT_13s0106g00790). This is a limiting enzyme of mevalonate isoprenoid pathway [104] responsible for the formation of sterols, which play an essential role in maintaining membranes structure and in preventing oxidative stress damages [105].

\section{Conclusions}

Understanding the genetic basis of grapevine drought stress response is crucial in the management of vineyards and in the breeding of new varieties in a changing climate. In the present research, some genetic regions related to the control of transpiration potentially involved in drought resilience and relevant for crop improvement were detected with a GWAS approach. The application of infrared thermography allowed evaluating the grapevine rootstocks response to water deficit reducing the time for collecting phenotypic data, and, thus, allowing the screening of numerous genotypes. Significant marker-trait associations were detected, despite the complexity of the trait under investigation and its polygenic inheritance. Additional studies on commercial rootstocks enabled us to point out several candidate genes (VIT_13s0019g03040, VIT_17s0000g08960, VIT 18s0001g15390) presumably implicated in response to water deficit, providing valuable information on important tolerance traits. These results highlighted a relevant role of a raffinose synthase, belonging to a family of oligosaccharides well known for protecting plants against abiotic stresses.

\section{Methods}

Plant material and construction of genetic core collection The association population consisted of one hundred non-vinifera genotypes (Vitis spp.) representing the genetic diversity of two more extensive germplasm collections maintained by Fondazione Edmund Mach (ITA362) [40] and University of Milan (ITA427). The material consisted of interspecific hybrids used for fruit production (Hybrids), rootstock varieties including wild non-vinifera Vitis species (Rootstocks/Wild) and rootstocks selected in a breeding program (Rootstocks Breeding). The MSTRAT software, which implements The Maximization (M) method [106, 107], was applied to construct this core collection, by performing 200 iterations per MSTRAT run and 100 repetitions for core sampling. Putative core collections with equal allelic richness were ordered according to Nei's diversity index [108]. The final core collection included the accessions that were more frequent in the 100 replicates.

\section{SNP genotyping, genetic diversity and genetic structure of the population}

DNA was isolated from leaves of rootstock genotypes with the DNeasy ${ }^{\circ}$ Plant Mini Kit (QIAGEN, Hilden, Germany). DNA quality was assessed using both agarose gel electrophoresis and the NanoDrop ND-8000 
spectrophotometer (NanoDrop Technologies, Wilmington, DE, USA).

The commercial GrapeReseq $20 \mathrm{~K}$ SNPs array was used to genotype the core collection with the Infinium technology following the manufacturer's instructions (Illumina, Inc., San Diego, CA, USA). The raw SNP data generated were scored and filtered according to Marrano et al. [34].

Genetic variability within and among groups was measured both for SSR and SNP loci. The mean number of alleles per locus (A), the number of effective alleles $\left(\mathrm{A}_{\mathrm{E}}\right.$, [109]), levels of observed $\left(\mathrm{H}_{\mathrm{O}}\right)$ and expected $\left(\mathrm{H}_{E}\right)$ heterozygosity [110] and the fixation index ( $\mathrm{F}$, inbreeding coefficient [111]) were calculated using GenAlex 6.502 [112].

The genetic structure of the association population was analyzed with STRUCTURE software v2.3.2 [113], which uses a variational Bayesian framework for approximate inference of subpopulations [114]. Ten independent runs for $\mathrm{K}$ values ranging from 1 to 7 were performed with the following parameters set (burn-in length/iterations) $500,000 / 750,000$ and 10,000/100,000 for SSR and SNP data, respectively. The admixture model was applied with no prior population information. Estimation of the most probable $\mathrm{K}$ value was obtained running the algorithm for multiple choices of $\mathrm{K}$ and visualizing the marginal likelihood and $\Delta \mathrm{K}$ [41] of the data over ten runs using STRUCTURE HARVESTER [115]. The optimal alignment of runs was analyzed with CLUMPP v1.1.2 [116]. Final results were visualized with the software DISTRUCT v1.1 [117].

A Discriminant Analysis of Principal Components (DAPC) [118] was performed to identify genetic clusters using the package adegenet of $\mathrm{R}$ software. The number of axes considered in the Principal Component Analysis (PCA) was determined with cross-validation (CV) function implemented in poppr package of $\mathrm{R}$ software [119].

\section{Water stress experiment conditions}

Six replicates of each grape genotype included in the association mapping panel were grown in a 5-L pot filled with a substrate composed of sandy loam soil and peat (4:1 in volume) under partially controlled climate conditions. Soil water content (SWC) was determined by the gravimetric method, from the difference in weight between the wet and the dry soil [120]. Two irrigation treatments were established. Three replicates were irrigated maintaining the $90 \%$ of SWC (well-watered plants, WW) and 3 replicates (water stressed plants, WS) were subjected to a gradual drought stress: a moderate stable water deficit ( $50 \%$ of SWC for 7 days), followed by a severe stable water deficit (30\% of SWC for 7 days) and a recovery period ( $90 \%$ for 5 days). This experiment was repeated for three years: $2012\left(1^{\circ}\right.$ year), $2013\left(2^{\circ}\right.$ year $)$ and for a subset population in 2014 ( $3^{\circ}$ year).

One-year-old potted $(9 \mathrm{~L})$ rooted cuttings of three selected rootstock varieties (101.14, SO4, RGM) were further grown and evaluated in a tunnel- greenhouse. Twelve replicates of each rootstock genotype were subjected to water stress by completely suspending irrigation for 15 days (WS), while 6 replicates were maintained at about $90 \%$ of maximum water availability (WW). The growing medium was composed of a sandpeat mixture (1:1 in volume) with a field capacity of $35 \%$ [(vol water/vol soil $) \times 100]$. The volumetric soil moisture content per pot was monitored with a ML3 ThetaProbe Soil Moisture Sensor (Delta-T Devices, London, UK). The pot surface was covered with a plastic film to avoid soil water evaporation. The experimental plan was completely randomized.

\section{Thermal indices and stomatal conductance estimation}

The physiological response to drought was evaluated over 30 days. To evaluate the effect of water stress thermal images of the grape leaf canopies were elaborated using the software InfReC Analyzer (NS9500LT) (Nippon Avionics Co., Yokohama, Japan). Stomatal conductance was estimated from two different thermal indices: crop water stress index (CSWI) (Eq. 1) [121] and thermal index (Ig) (Eq. 2) [122].

$$
\begin{aligned}
& C W S I=\frac{T_{\text {canopy }}-T_{\text {wet }}}{T_{d r y}-T_{\text {wet }}} \\
& I G=\frac{T_{\text {dry }}-T_{\text {canopy }}}{T_{\text {canopy }}-T_{\text {wet }}}
\end{aligned}
$$

where $\mathrm{T}_{\text {canopy }}\left({ }^{\circ} \mathrm{C}\right)$ was the temperature deduced from the thermal images of six sun-exposed mature leaves per vine, $\mathrm{T}_{\mathrm{dry}}\left({ }^{\circ} \mathrm{C}\right)$ and $\mathrm{T}_{\text {wet }}\left({ }^{\circ} \mathrm{C}\right)$ were the temperatures detected on the cardboard "reference surfaces". Stomatal conductance $\left(\mathrm{g}_{\mathrm{s}}\right)$ and transpiration were measured with a steady state porometer (Licor Li-1600) in the third experimental year.

\section{GWAS analysis}

Genotype-phenotype associations were tested considering the average value of each trait for each year separately. When phenotype scores were not normally distributed they were transformed using the logarithm function. Three different models were tested using TASSEL v.5.2 [123]. The first model applied was the General Linear Model (GLM), which considers the population structure calculated with principal component analysis (PCA) as a cofactor. The following matrix notation describes the GLM model:

$$
y_{i}=\mu+x_{i} \beta+Q v+\varepsilon
$$


where $y_{i}$ is the phenotypic value of $i^{\text {th }}$ sample, $\mu$ is the model intercept, $\beta$ is a vector of SNP effects, $v$ is a vector of population effect and $\varepsilon$ is a vector of residual effects, $\mathrm{Q}$ is the matrix from STRUCTURE that considers the individual probabilities to be associated to a subpopulation. The second model employed was the Mixed Linear model (MLM), which extends eq. (3) taking also into account a kinship matrix (K) to estimate the degree of genetic covariance between pairs of individuals [124]. The method of Endelman and Jannink [125] was applied to determine a centered identical-by-state $K$. The third model $(\mathrm{Q}+\mathrm{K}$ model $)$ including both a fixed effect as the population structure matrix $(\mathrm{Q})$ and a random effect as the kinship matrix $(\mathrm{K})$. The marker trait association was evaluated by plotting quantile-quantile (Q-Q) plot. Pvalues adjustment for multiple testing was adopted: in addition to the Bonferroni-corrected critical $p$-values, qvalues were also calculated based on their corresponding p-values to identify significant associations between a trait and the SNPs. The q-value is a measure of significance in terms of False Discovery Rate (FDR) [126] that limits the false positive results while offering a more liberal criterion than Bonferroni correction factor. A $q$ value of 0.1 was used as significant association threshold [127]. GWAS results were visualized with Manhattan plots that were yielded from the qqman and CMplot packages of R software [128]. Genomic regions closest to the markers significantly associated with phenotypes were explored to identify candidate genes. Taking into account the extent of Linkage Disequilibrium (LD), a window of $10 \mathrm{~kb}$ upstream and downstream from associated loci was considered on the grape genome assembly v.2.1, hosted on http://genomes.cribi.unipd.it/grape [129].

\section{VIT_17s0000g08960 gene resequencing and genetic variation analysis}

Gene-specific primers were designed using Primer 3 software [130] based on the genomic sequence of $V$. vinifera gene annotation v2.1. An assembled contiguous sequence of $3678 \mathrm{bp}$ of the VIT_17s0000g08960 locus was resequenced with primers listed in Table S5 according to methods previously described [131].

The estimation and frequency of polymorphisms were defined using the DnaSP software [132], based on the SNPs and INDELs detected in VIT_17s0000g08960 coding region. Nucleotide diversity was estimated as $\pi$ [133]. The neutral mutation parameter $\theta$ [134] was estimated from the total amount of mutations. The hypothesis of neutral polymorphisms was tested using Tajima's D [135] and Fu and Li's D [136] tests. Prediction of tolerability of amino acid substitution at all positions was calculated with the software tool PROVEAN (Protein Variation Effect Analyzer) [137].

\section{Real-time qPCR}

Total RNA was isolated from grape leaves using the Spectrum $^{\mathrm{TM}}$ Plant Total RNA Kit (Sigma Aldrich, St. Louis, MO, USA). DNase treatment was performed using the Dnase I (Qiagen, Valencia, CA, USA) during the RNA extraction. RNA samples were quantified with the spectrophotometer NanoDrop ND-8000 (NanoDrop Technologies, Wilmington, DE, USA) and their integrity was checked by agarose gel electrophoresis. cDNA was synthesized with the SuperScript ${ }^{\oplus}$ III Reverse Transcriptase (Invitrogen, Carlsbad, CA, USA). Analysis of candidate genes expression was carried out using LightCycler ${ }^{\bullet}$ instrument and the related LightCycler ${ }^{\ominus}$ software (Roche Diagnostics, Basel, Switzerland). All Real-Time PCR reactions were performed using LightCycler ${ }^{\circledR} 480$ SYBR Green I Master Mix (Roche Diagnostics, Basel, Switzerland) in $20 \mu \mathrm{l}$ reactions according to to manufacturer's instructions by using primers listed in Table S6. Three independent biological replicates for each time point were analyzed. Gene expression levels were assessed with qbasePLUS software (Biogazelle, Zwijnaarde, Belgium [138]) and normalized by the reference genes Actin and Glyceraldehyde-3-phosphate dehydrogenase.

\section{Statistical analyses}

Statistical analyses were performed using $\mathrm{R}$ packages 'stats', 'agricolae' and 'companion' v3.5.1 (R Core Team, 2013). Different tests were applied for mean comparisons. Parametric Student's t-test or one-way ANOVA were used to compare normally distributed data with equal variances. Non-parametric Mann-Whitney U test and one-way Kruskal-Wallis test were applied when the assumptions of normality or homogeneity of variances were violated.

\section{Supplementary Information}

The online version contains supplementary material available at https://doi. org/10.1186/s12870-020-02739-z.

\section{Additional file 1. \\ Additional file 2. \\ Additional file 3. \\ Additional file 4. \\ Additional file 5 . \\ Additional file 6 . \\ Additional file 7. \\ Additional file 8. \\ Additional file 9.}

\section{Abbreviations}

GWAS: Genome-wide association study; WUE: Water-use efficiency; NIR: Near infrared; MAF: Minor allele frequency; SSR: Simple sequence repeat; SNP: Single-nucleotide polymorphism; CSWI: Crop water stress index; WS: Water stress; FDR: False discovery rate; LD: Linkage disequilibrium; 110R: 110 Richter; SO4: Selection Oppenheim 4; RGM: Riparia Gloire de Montpellier; 101.14: 101.14 Millardet et de Grasset; WW: Well-watered; 
NPQ: Non-photochemical quenching; QTL: Quantitative trait locus; FC: Field capacity; RFO: Raffinose family of oligosaccharides; ABA: Abscisic acid; ABRE: ABA-responsive elements; DREB: Dehydration-responsive element binding; MVD: Mevalonate diphosphate decarboxylase; DAPC: Discriminant analysis of principal components; SWC: Soil water content; GLM: General linear model; MLM: Mixed linear model

\section{Acknowledgements}

The authors thank Prof. Giovanni Battista Tornielli and Prof. Anita Zamboni (University of Verona) for their helpful discussions and suggestions, Dr. Paula Moreno-Sanz for her critically reading of the manuscript and the language revision, and Prof. Attilio Scienza (University of Milano) for his support. F.E. and MT wish to acknowledge the support of grants from AGER SERRES (Project N. 2010-2105) and WINEGRAFT.

\section{Authors' contributions}

FE and MSG conceived and designed the research work; MSG acquired the financial support and supervised the research activity; MT, FE, SL, PLB, DG and OF took part in the experimental work; MT and FE performed the statistical analyses and were involved in data interpretation; MT wrote the manuscript. All the authors reviewed, edited and approved the final version of the manuscript.

\section{Funding}

This work was jointly funded by CAVIT s.c. (Trento) and Fondazione Edmund Mach (San Michele all'Adige, Trento). The funding body had no role in the design of the study and collection, analysis, and interpretation of data and in writing the manuscript.

\section{Availability of data and materials}

All data generated during this study are included within the article and in its supplementary information files or are available from the corresponding author on reasonable request. Nucleotide sequences of VIT_17s0000g08960 can be found in the GenBank data libraries under the accession numbers: MW066760, MW066761, MW066762, MW066763, MW066764, MW066765, MW066766, MW066767, MW066768, MW066769, MW066770, MW066771, MW066772, MW066773, MW066774, MW066775, MW066776, MW066777, MW066778, MW066779, MW066780, MW066781, MW066782, MW066783, MW066784, MW066785, MW066786, MW066787, MW066788, MW066789, MW066790, MW066791, MW066792, MW066793, MW066794, MW066795, MW066796, MW066797, MW066798, MW066799, MW066800, MW066801, MW066802, MW066803, MW066804, MW066805, MW066806, MW066807, MW066808, MW066809, MW066810, MW066811, MW066812, MW066813, MW066814, MW066815, MW066816, MW066817, MW066818, MW066819, MW066820, MW066821, MW066822, MW066823, MW066824, MW066825, MW066826, MW066827, MW066828, MW066829, MW066830, MW066831, MW066832, MW066833, MW066834, MW066835, MW066836, MW066837, MW066838, MW066839, MW066840, MW066841, MW066842, MW066843, MW066844.

\section{Ethics approval and consent to participate} Not applicable.

\section{Consent for publication}

Not applicable.

\section{Competing interests}

The authors declare that they have no competing interests.

\section{Author details}

${ }^{1}$ Research and Innovation Centre, Fondazione Edmund Mach, via E. Mach 1, 38010 San Michele all'Adige, Italy. ${ }^{2}$ Technology Transfer Centre, Fondazione Edmund Mach, via E. Mach 1, 38010 San Michele all'Adige, Italy. ${ }^{3}$ Department of Agricultural and Environmental Sciences, University of Milano, via Celoria 2, 20133 Milan, Italy. ${ }^{4}$ Center Agriculture Food Environment (C3A), University of Trento, via E. Mach 1, 38010 San Michele all'Adige, Italy.
Received: 1 April 2020 Accepted: 16 November 2020 Published online: 06 January 2021

\section{References}

1. IPCC (2018). Global warming of $1.5^{\circ} \mathrm{C}$, an IPCC special report on the impacts of global warming of $1.5^{\circ} \mathrm{C}$ above pre-industrial levels and related global greenhouse gas emission pathways, in the context of strengthening the global response to the threat of climate change, sustainable development, and efforts to eradicate poverty. Summary for policy makers, available online at: http://report.ipcc.ch/sr15/pdf/sr15_spm_final.pdf. Accessed 17 Oct 2019

2. Tollefson J. Clock ticking on climate action. Nature. 2018;562:172-3.

3. Boyer JS, Byrne P, Cassman KG, Cooper M, Delmer D, Greene T, Gruis F, Habben J, Hausmann N, Kenny N, Lafitte R, Paszkiewicz S, Porter D, Schlegel A, Schussler J, Setter T, Shanahan J, Sharp RE, Vyn TJ, Warner D, Gaffney J. The U.S. drought of 2012 in perspective: a call to action. Glob Food Secur. 2013;2:139-43.

4. Hannah L, Roehrdanz PR, Ikegami M, Shepard AV, Shaw MR, Tabor G, Zhi L, Marquet PA, Hijmans RJ. Climate change, wine, and conservation. Proc Natl Acad Sci U S A. 2013:110:6907-12.

5. Van Leeuwen C, Schultz HR, Garcia de Cortazar-Atauri I, Duchene E, Ollat N, Pieri P, Bois B, Goutouly JP, Quenol H, Touzard JM, Malheiro A, Bavarescok L, Delrot $\mathrm{S}$. Why climate change will not dramatically decrease viticultural suitability in main wine-producing areas by. Proc Natl Acad Sci U S A. 2013; 110:3051-2

6. Mosedale JR, Wilson RJ, Maclean IMD. Climate change and crop exposure to adverse weather: changes to frost risk and grapevine flowering conditions. PLoS One. 2015:10:e0141218.

7. Charrier G, Delzon S, Domec JC, Zhang L, Delmas CEL, Merlin I, Corso D, King A, Ojeda H, Ollat N, Prieto JA, Scholach H, Skinner P, van Leeuwen C, Gambetta GA. Drought will not leave your glass empty: Low risk of hydraulic failure revealed by long-term drought observations in world's top wine regions. Sci Adv. 2018:4:eaa06969.

8. Dos Santos TP, Lopes CM, Rodrigues ML, de Souza CR, Maroco JP, Pereira JS, Silva JR, Chaves MM. Partial rootzone drying: effects on growth and fruit quality of field grown grapevines. Funct Plant Biol. 2003;30:663-71.

9. Savoi S, Wong DCJ, Arapitsas P, Miculan M, Bucchetti B, Peterlunger E, Fait A, Mattivi F, Castellarin SD. Transcriptome and metabolite profiling reveals that prolonged drought modulates the phenylpropanoid and terpenoid pathway in white grapes (Vitis vinifera L.). BMC Plant Biol. 2016;16:67.

10. Kissoudis C, van de Wiel C, Visser RGF, Van Der Linden G. Enhancing crop resilience to combined abiotic and biotic stress through the dissection of physiological and molecular crosstalk. Front Plant Sci. 2014;5:207.

11. Simonneau T, Lebon E, Coupel-Ledru A, Marguerit E, Rossdeutsch L, Ollat N. Adapting plant material to face water stress in vineyards: which physiological targets for an optimal control of plant water status? OENO One. 2017;51:2.

12. Chaves MM, Oliveira MM. Mechanisms underlying plant resilience to water deficits: prospects for water-saving agriculture. J Exp Bot. 2004;55:2365-84.

13. Hochberg U, Windt CW, Ponomarenko A, Zhang Y-J, Gersony J, Rockwell FE, Holbrook NM. Stomatal closure, basal leaf embolism, and shedding protect the hydraulic integrity of grape stems. Plant Physiol. 2017;174:764-75.

14. Lovisolo C, Hartung W, Schubert A. Whole-plant hydraulic conductance and root-to-shoot flow of abscisic acid are independently affected by water stress in grapevines. Funct Plant Biol. 2002;29:1349-56.

15. Pillet J, Egert A, Pieri P, Lecourieux F, Kappel C, Charon J, Gomès E, Keller F, Delrot S, Lecourieux D. VvGOLS1 and VVHsfA2 are involved in the heat stress responses in grapevine berries. Plant Cell Physiol. 2012;53:1776-92.

16. Carvalho LC, Vidigal P, Amâncio S. Oxidative stress homeostasis in grapevine (Vitis vinifera L.). front. Environ Sci. 2015;3:20.

17. Degu A, Hochberg U, Wong DCJ, Alberti G, Lazarovitch N, Peterlunger $E$, Castellarin SD, Herrera JC, Fait A. Swift metabolite changes and leaf shedding are milestones in the acclimation process of grapevine under prolonged water stress. BMC Plant Biol. 2019;19:69.

18. Conde A, Regalado A, Rodrigues D, Costa JM, Blumwald E, Chaves MM, Gerós H. Polyols in grape berry: transport and metabolic adjustments as a physiological strategy for water-deficit stress tolerance in grapevine. J Exp Bot. 2015;66:889-906.

19. Vandeleur RK, Mayo G, Shelden MC, Gilliham M, Kaiser BN, Tyerman SD. The role of plasma membrane intrinsic protein aquaporins in water transport through roots: diurnal and drought stress responses reveal different 
strategies between isohydric and anisohydric cultivars of grapevine. Plant Physiol. 2009;149:445-60.

20. Lovisolo C, Perrone I, Carra A, Ferrandino A, Flexas J, Medrano H, Schubert A. Drought-induced changes in development and function of grapevine (Vitis spp.) organs and in their hydraulic and non-hydraulic interactions at the whole-plant level: a physiological and molecular update. Funct Plant Biol. 2010;37:98-116

21. Perrone I, Gambino G, Chitarra W, Vitali M, Pagliarani C, Riccomagno N, Balestrini R, Kaldenhoff R, Uehlein N, Gribaudo I, Schubert A, Lovisolo C. The grapevine root-specific aquaporin VVPIP2; $4 \mathrm{~N}$ controls root hydraulic conductance and leaf gas exchange under well-watered conditions but not under water stress. Plant Physiol. 2012;160:965-77.

22. Gambetta GA, Manuck CM, Drucker ST, Shaghasi T, Fort K, Matthews MA, Walker MA, McElrone AJ. The relationship between root hydraulics and scion vigour across Vitis rootstocks: what role do root aquaporins play? J Exp Bot. 2012;63:6445-55.

23. Serra I, Strever A, Myburgh PA, Deloire A. Review: the interaction between rootstocks and cultivars (Vitis vinifera L.) to enhance drought tolerance in grapevine. Aust J Grape Wine Res. 2014;20:1-14.

24. Marguerit E, Brendel O, Lebon E, Van Leeuwen C, Ollat N. Rootstock control of scion transpiration and its acclimation to water deficit are controlled by different genes. New Phytol. 2012;194:416-29.

25. Tramontini S, Vitali M, Centioni L, Schubert A, Lovisolo C. Rootstock control of scion response to water stress in grapevine. Environ Exp Bot. 2013;93:206.

26. Peccoux A, Loveys B, Zhu J, Gambetta GA, Delrot S, Vivin P, Schultz HR, Ollat $\mathrm{N}$, Dai Z. Dissecting the rootstock control of scion transpiration using model-assisted analyses in grapevine. Tree Physiol. 2017;38:1026-40.

27. Cookson SJ, Clemente-Moreno MJ, Hevin C, Mendome LZ, Delrot S, TrossatMagnin C, Ollat N. Graft union formation in grapevine induces transcriptional changes related to cell wall modification, wounding, hormone signalling, and secondary metabolism. J Exp Bot. 2013;64:29973008.

28. Chitarra W, Perrone I, Avanzato CG, Minio A, Boccacci P, Santini D, Gilardi G, Siciliano I, Gullino ML, Delledonne M, Mannini F, Gambino G. Grapevine grafting: Scion transcript profiling and defense-related metabolites induced by rootstocks. Front Plant Sci. 2017;8:654.

29. Yang $Y$, Mao L, Jittayasothorn $Y$, Kang $Y$, Jiao C, Fei Z, Zhong GY. Messenger RNA exchange between scions and rootstocks in grafted grapevines. BMC Plant Biol. 2015;15:251.

30. Pagliarani C, Vitali M, Ferrero M, Vitulo N, Incarbone M, Lovisolo C, Valle G, Schubert A. Accumulation of MicroRNAs differentially modulated by drought is affected by grafting in grapevine. Plant Physiol. 2017;173:218095.

31. Coupel-Ledru A, Lebon É, Christophe A, Doligez A, Cabrera-Bosquet L, Péchier $P$, Hamard $P$, This $P$, Simonneau T. Genetic variation in a grapevine progeny (Vitis vinifera L. cvs Grenache Syrah) reveals inconsistencies between maintenance of daytime leaf water potential and response of transpiration rate under drought. J Exp Bot. 2014;65:6205-18.

32. Guo D, Zhao HL, Li Q, Zhang GH, Jiang JF, Liu CH, Yu YH. Genome-wide association study of berry- related traits in grape [Vitis vinifera L.] based on genotyping-by-sequencing markers. Hortic. Res. 2019;6:11.

33. Chitwood DH, Ranjan A, Martinez C, Headland L, Thiem T, Kumar R, Covington MF, Hatcher T, Naylor DT, Zimmerman S, Downs N, Raymundo N, Buckler ES, Maloof JN, Aradhya M, Prins B, Li L, Myles S, Sinha N. A modern ampelography: a genetic basis for leaf shape and venation patterning in grape. Plant Physiol. 2014;164:259-72.

34. Marrano A, Micheletti D, Lorenzi S, Neale D, Grando MS. Genomic signatures of different adaptations to environmental stimuli between wild and cultivated Vitis vinifera L. Hort J. 2018;5:34.

35. Tuberosa R. Phenotyping for drought tolerance of crops in the genomics era. Front Physiol. 2012;3:347.

36. Ghozlen NB, Cerovic ZG, Germain C, Toutain S, Latouche G. Non-destructive optical monitoring of grape maturation by proximal sensing. Sensors. 2010; 10:10040.

37. Kicherer A, Herzog K, Bendel N, Klück HC, Backhaus A, Wieland M, Rose JC, Klingbeil L, Läbe T, Hohl C, Petry W, Kuhlmann H, Seiffert U, Töpfer R. Phenoliner: a new field Phenotyping platform for grapevine research. Sensors. 2017;17:1625.

38. Gago J, Fernie AR, Nikoloski Z, Tohge T, Martorell S, Escalona JM, RibasCarbó M, Flexas J, Medrano H. Integrative field scale phenotyping for investigating metabolic components of water stress within a vineyard. Plant Methods. 2017;13:90

39. Bianchi D, Grossi D, Tincani DTG, Simone Di Lorenzo G, Brancadoro L, Rustioni L. Multi-parameter characterization of water stress tolerance in Vitis hybrids for new rootstock selection. Plant Physiol Biochem. 2018;15:333-40.

40. Emanuelli F, Lorenzi S, Grzeskowiak L, Catalano V, Stefanini M, Troggio M, Myles M, Martinez-Zapater JM, Zyprian E, Moreira FM, Grando MS. Genetic diversity and population structure assessed by SSR and SNP markers in a large germplasm collection of grape. BMC Plant Biol. 2013;13:39.

41. Evanno G, Regnaut S, Goudet J. Detecting the number of clusters of individuals using the software structure: a simulation study. Mol Ecol. 2005; 14:2611-20.

42. Le Cunff L, Fournier-Level A, Laucou V, Vezzulli S, Lacombe T, AdamBlondon AF, Boursiquot JM, This P. Construction of nested genetic core collections to optimize the exploitation of natural diversity in Vitis vinifera $\mathrm{L}$ subsp sativa. BMC Plant Biol. 2008;8:31.

43. Nicolas SD, Péros JP, Lacombe T, Launay A, Le Paslier MC, Bérard A, Mangin $B$, Valière S, Martins F, Le Cunff L, Laucou V, Bacilieri R, Dereeper A, Chatelet $P$, This $P$, Doligez A. Genetic diversity, linkage disequilibrium and power of a large grapevine (Vitis vinifera $L$ ) diversity panel newly designed for association studies. BMC Plant Biol. 2016;16:74.

44. Myles S, Boyko AR, Owens CL, Brown PJ, Grassi F, Aradhya MK, Prins B, Reynolds A, Chia J-M, Ware D, Bustamante CD, Buckler ES. Genetic structure and domestication history of the grape. Proc Natl Acad Sci U S A. 2011;108:3530-5.

45. McKhann HI, Camilleri C, Berard A, Bataillon T, David JL, Reboud X, Le Corre V, Caloustian C, Gut IG, Brunel D. Nested core collections maximizing genetic diversity in Arabidopsis thaliana. Plant J. 2004;38:193-202.

46. Zhang P, Liu X, Tong H, Lu Y, Li J. Association mapping for important agronomic traits in core collection of rice (Oryza sativa L.) with SSR markers. PLoS One. 2014;9:e111508.

47. Campoy JA, Lerigoleur-Balsemin E, Christmann H, Beauvieux R, Girollet N, Quero-García J, Dirlewanger E, Barreneche T. Genetic diversity, linkage disequilibrium, population structure and construction of a core collection of Prunus avium L. landraces and bred cultivars. BMC Plant Biol. 2016;16:1.

48. Zhang H, Wang ML, Schaefer R, Dang P, Jiang T, Chen C. GWAS and coexpression network reveal lonomic variation in cultivated Peanut. J Agric Food Chem. 2019;67:12026-36.

49. Liang ZC, Duan SC, Sheng J, Zhu SS, Ni XM, Shao JH, Liu CH, Nick P, Du F, Fan PG, Mao RZ, Zhu YF, Deng WP, Yang M, Huang HC, Liu YX, Ding YQ, Liu $X J$, Jiang JF, Zhu YY, He XH, Chen W, Li SH, Dong Y. Whole-genome resequencing of 472 Vitis accessions for grapevine diversity and demographic history analyses. Nat Commun. 2019;10:1190.

50. Pereira-Lorenzo S, Ramos-Cabrera AM, Ferreira V, Díaz-Hernández MB, Carnide V, Pinto-Carnide O, Rodrigues R, Velázquez-Barrera ME, Rios-Mesa D, Ascasíbar-Errastie J, Castro I. Genetic diversity and core collection of Malus $\times$ domestica in northwestern T Spain, Portugal and the Canary Islands by SSRs. Sci Hort. 2018;240:49-56.

51. Ellwood SR, D'Souza NK, Kamphuis LG, Burgess TI, Nair RM, Oliver RP. SSR analysis of the Medicago truncatula SARDI core collection reveals substantial diversity and unusual genotype dispersal throughout the Mediterranean basin. Theor Appl Genet. 2006;112(5):977-83.

52. Jones ES, Sullivan $H$, Bhattramakki D, Smith JSC. A comparison of simple sequence repeat and single nucleotide polymorphism marker technologies for the genotypic analysis of maize (Zea mays L). Theor Appl Genet. 2007;115:361-71.

53. Tsykun T, Rellstab C, Dutech C, Sipos G, Prospero S. Comparative assessment of SSR and SNP markers for inferring the population genetic structure of the common fungus Armillaria cepistipes. Heredity. 2017;119:371-80.

54. Cabezas JA, Ibáñez J, Lijavetzky D, Vélez D, Bravo G, Rodríguez V, Carreño I, Jermakow AM, Carreño J, Ruiz-García L, Thomas MR, Martinez-Zapater JM. A 48 SNP set for grapevine cultivar identification. BMC Plant Biol. 2011;11:153.

55. De Lorenzis G, Chipashvili R, Failla O, Maghradze D. Study of genetic variability in Vitis vinifera L. germplasm by high-throughput Vitis18kSNP array: the case of Georgian genetic resources. BMC Plant Biol. 2015;5:154.

56. Töpfer R, Hausmann L, Harst M, Maul E, Zyprian E, Eibach R. New horizons for grapevine breeding. Fruit Veg Cereal Sci Biotechnol. 2011:5:79-100.

57. Chaves MM, Zarrouk O, Francisco R, Costa JM, Santos T, Regalado AP, Rodrigues ML, Lopes CM. Grapevine under deficit irrigation: hints from physiological and molecular data. Ann Bot. 2010;105:661-76.

58. Matese A, Baraldi R, Berton A, Cesaraccio C, Di Gennaro SF, Duce P, Facini O, Mameli MG, Piga A, Zaldei A. Estimation of water stress in grapevines using proximal and remote sensing methods. Rem Sens. 2018;10:114. 
59. Blum A, Mayer J, Gozlan G. Infrared thermal sensing of plant canopies as a screening technique for dehydration avoidance in wheat. Field Crops Res. 1982;5:137-46.

60. Bellvert J, Zarco-Tejada PJ, Girona J, Fereres E. Mapping crop water stress index in a 'pinot-noir' vineyard: comparing ground measurements with thermal remote sensing imagery from an unmanned aerial vehicle. Precis Agric. 2014;15:361-76.

61. Sepulveda-Reyes D, Ingram B, Bardeen M, Zuñiga M, Ortega-Farıas S, Poblete-Echeverra C. Selecting canopy zones and Thresholding approaches to assess grapevine water status by using aerial and ground-based thermal imaging. Remote Sens. 2016;8:822.

62. Coupel-Ledru A, Pallas B, Delalande M, Boudon F, Carrié E, Martinez S, Regnard J, Costes E. Multi-scale high-throughput phenotyping of apple architectural and functional traits in orchard reveals genotypic variability under contrasted watering regimes. Hort J. 2019;6:52.

63. $X u$ Y, Li P, Yang Z, Xu C. Genetic mapping of quantitative trait loci in crops. The Crop J. 2017:5:175-84

64. Fodor A, Segura V, Denis M, Neuenschwander S, Fournier-Level A, Chatelet P, Homa FAA, Lacombe T, This P, Le CL. Genome-wide prediction methods in highly diverse and heterozygous species: Proof-of-concept through simulation in grapevine. PLoS One. 2014;9:e11.

65. Tello J, Torres-Pérez R, Grimplet J, Ibáñez J. Association analysis of grapevine bunch traits using a comprehensive approach. Theor Appl Genet. 2016;119: 227-42

66. Laucou V, Launay A, Bacilieri R, Lacombe T, Adam-Blondon AF, Bérard A, Chauveau A, de Andrés MT, Hausmann L, Ibáñez J, Le Paslier MC, Maghradze D, Martinez-Zapater JM, Maul E, Ponnaiah M, Töpfer R, Péros JP, Boursiquot JM. Extended diversity analysis of cultivated grapevine Vitis vinifera with 10K genome-wide SNPS. PLoS One. 2018;13:e0192540.

67. Carbonneau A. The early selection of grapevine rootstocks for resistance to drought conditions. Am J Enol Vitic. 1985;36:195-8.

68. Boso S, Alonso-Villaverde V, Gago P, Santiago JL, Martínez MC. Susceptibility to downy mildew (Plasmopara viticola) of different Vitis varieties. Crop Prot. 2014;63:26-35.

69. Marrano A, Birolo G, Prazzoli ML, Lorenzi S, Valle G, Grando MS. SNPDiscovery by RAD-Sequencing in a germplasm collection of wild and cultivated grapevines (V. vinifera L.). PLoS ONE. 2017;12:e0170655.

70. Soar C, Dry P, Loveys B. Scion photosynthesis and leaf gas exchange in Vitis vinifera L. Cv. Shiraz: mediation of rootstock effects via xylem sap ABA. Aust J Grape Wine Res. 2006;12:82-96.

71. Koundouras S, Tsialtas IT, Zioziou E, Nikolaou N. Rootstock effects on the adaptive strategies of grapevine (Vitis vinifera L. cv. Cabernet-sauvignon) under contrasting water status: leaf physiological and structural responses. Agric Ecosyst Environ. 2008;128:86-96.

72. Zandalinas SI, Mittler R, Balfagon D, Arbona V, Gómez-Cadenas A. Plant adaptations to the combination of drought and high temperatures. Physiol Plant. 2017:162:2-12

73. Sengupta S, Mukherjee S, Basak P, Majumder AL. Significance of galactinol and raffinose family oligosaccharide synthesis in plants. Front Plant Sci. 2015;6:656.

74. Taji T, Oshumi C, luchi S, Seki M, Kasuga M, Kobayashi M, YamaguchiShinozaki K, Shinozaki K. Important roles of drought and cold inducible genes for galactinol synthase in stress tolerance in Arabidopsis thaliana. Plant J. 2002:29:417-26.

75. Nishizawa A, Yabuta Y, Shigeoka S. Galactinol and raffinose constitute a novel function to protect plants from oxidative damage. Plant Physiol. 2008; 147:1251-63.

76. Sun Z, Qi X, Wang Z, Li P, Wu C, Zhang H, Zhao Y. Overexpression of TsGOLS2, a galactinol synthase, in Arabidopsis thaliana enhances tolerance to high salinity and osmotic stresses. Plant Physiol Biochem. 2013;69:82-9.

77. Kang Y, Han Y, Torres-Jerez I, Wang M, Tang Y, Monteros M, Udvardi M. System responses to long-term drought and re-watering of two contrasting alfalfa varieties. Plant J. 2011;68:871-89.

78. Peters S, Mundree SG, Thomson JA, Farrant JM, Keller F. Protection mechanisms in the resurrection plant Xerophyta viscosa (baker): both sucrose and raffinose family oligosaccharides (RFOs) accumulate in leaves in response to water deficit. J Exp Bot. 2007;58:1947-56.

79. Gu L, Zhang Y, Zhang M, Li T, Dirk LM, Downie B, Zhao T. ZmGOLS2, a target of transcription factor ZmDREB2A, offers similar protection against abiotic stress as ZmDREB2A. Plant Mol Biol. 2015;90:157-70.

80. Dos Santos TB, de Lima RB, Nagashima GT, Petkowicz CL, Carpentieri-Pipolo V, Pereira LFP, Domingues DS, Vieira LGE. Galactinol synthase transcriptional profile in two genotypes of Coffea canephora with contrasting tolerance to drought. Genet Mol Biol. 2015;38:182-90.

81. Falavigna VS, Porto DD, Miotto YE, Santos HPD, Oliveira PRD, MargisPinheiro M, Pasquali G, Revers LF. Evolutionary diversification of galactinol synthases in Rosaceae: adaptive roles of galactinol and raffinose during apple bud dormancy. J Exp Bot. 2018;69:1247-59.

82. Savi T, González AG, Herrera JC, Forneck A. Gas exchange, biomass and non-structural carbohydrates dynamics in vines under combined drought and biotic stress. BMC Plant Biol. 2019;19:408.

83. Kang Y, Outlaw WH Jr, Fiore GB, Riddle KA. Guard cell apoplastic photosynthate accumulation corresponds to a phloem-loading mechanism. J Exp Bot. 2007:58:4061-70.

84. Daloso M, dos Anjos L, Fernie AR. Roles of sucrose in guard cell regulation. New Phytol. 2016;211:809-18.

85. Dal Santo S, Palliotti A, Zenoni S, Tornielli GB, Fasoli M, Paci P, Tombesi S, Frioni T, Silvestroni O, Bellincontro A, d'Onofrio C, Matarese F, Gatti M, Poni $\mathrm{S}$, Pezzotti M. Distinct transcriptome responses to water limitation in isohydric and anisohydric grapevine cultivars. BMC Genomics. 2016;17:815.

86. Nicolas P, Lecourieux D, Kappel C, Cluzet S, Cramer G, Delrot S, Lecourieux F. The basic leucine zipper transcription factor ABSCISIC ACID RESPONSE ELEMENT-BINDING FACTOR2 is an important transcriptional regulator of abscisic acid-dependent grape berry ripening processes. Plant Physiol. 2014; 164:365-83.

87. Pilati S, Bagagli G, Sonego P, Moretto M, Brazzale D, Castorina G, Simoni L, Tonelli C, Guella G, Engelen K, Galbiati M, Moser C. Abscisic acid is a major regulator of grape berry ripening onset: new insights into $A B A$ signaling network. Front Plant Sci. 2017:8:1093.

88. Egert A, Keller F, Peters S. Abiotic stress-induced accumulation of raffinose in Arabidopsis leaves is mediated by a single raffinose synthase (RS5, At5g40390). BMC Plant Biol. 2013;13:e218.

89. Iwasaki T, Yamaguchi-Shinozaki K, Shinozaki Kl. Identification of a cisregulatory region of a gene in Arabidopsis thaliana whose induction by dehydration is mediated by abscisic acid and requires protein synthesis. Mol Gen Genet. 1995:247:391-8.

90. Kang JY, Choi HI, Im MY, Kim SY. Arabidopsis basic leucine zipper proteins that mediate stress-responsive abscisic acid signaling. Plant Cell. 2002;14:343-57.

91. Dubouzet JG, Sakuma Y, Ito Y, Kasuga M, Dubouzet EG, Miura S, Seki M, Shinozaki K, Yamaguchi-Shinozaki K. OsDREB genes in rice, Oryza sativa L., encode transcription activators that function in drought-, high-, salt- and cold-responsive gene expression. Plant J. 2003;33:751-63.

92. Narusaka Y, Nakashima K, Shinwari ZK, Sakuma Y, Furihata T, Abe H, Narusaka M, Shinozaki K, Yamaguchi-Shinozaki K. Interaction between two cis-acting elements, ABRE and DRE, in ABA-dependent expression of Arabidopsis rd29A gene in response to dehydration and high-salinity stresses. Plant J. 2003;34:137-48.

93. Simpson SD, Nakashima K, Narusaka Y, Seki M, Shinozaki K, YamaguchiShinozaki K. Two different novel cis-acting elements of erd1, a clpA homologous Arabidopsis gene function in induction by dehydration stress and dark-induced senescence. Plant J. 2003;33:259-70.

94. Owens CL. SNP detection and genotyping in Vitis. Acta Hortic. 2003;603:139-40

95. Lijavetzky D, Cabezas JA, Ibanez A, Rodriguez V, Martinez-Zapater JM. High throughput SNP discovery and genotyping in grapevine (Vitis vinifera L.) by combining a re-sequencing approach and SNPlex technology. BMC Genomics. 2007;8:424.

96. Fernandez L, Le Cunff L, Tello J, Lacombe T, Boursiquot JM, Fournier-Level A, Bravo G, Lalet S, Torregrosa L, This P. Mar- tinez-Zapater JM. Haplotype diversity of VVTFL1A gene and association with cluster traits in grapevine (V. vinifera). BMC Plant Biol. 2014;14:209.

97. Zhou Y, Massonnet M, Sanjak JS, Cantu D, Gaut BS. Evolutionary genomics of grape (Vitis ssp. vinifera) domestication. Proc Natl Acad Sci USA. 2017; 114(44):11.

98. Barceló AR, Pomar F, Lopez-Serano M, Pedreno MA. Peroxidase: a multifunctional enzyme in grapevines. Funct Plant Biol. 2003;30:557-91.

99. Mittler R, Vanderauwera S, Gollery M, Van Breusegem F. Reactive oxygen gene network of plants. Trends Plant Sci. 2004;9:490-8.

100. Castelletti S, Tuberosa R, Pindo M, Salvi S. A MITE transposon insertion is associated with differential methylation at the maize flowering time QTL Vgt1. G3-Genes Genom Genet. 2014:4:805-12.

101. Liu Z, Yan J, Li DK, Luo Q, Yan Q, Liu ZB, Ye LM, Wang JM, Li XF, Yang Y. UDP-glucosyltransferase 71c5, a major glucosyltransferase, mediates abscisic acid homeostasis in Arabidopsis. Plant Physiol. 2015;167:1659-70. 
102. Li Y, Wang B, Dong R, Hou B. AtUGT76C2, an Arabidopsis cytokinin glycosyltransferase is involved in drought stress adaptation. Plant Sci. 2015; 236:157-67.

103. Rehman HM, Nawaz MA, Shah ZH, Ludwig-Müller J, Chung G, Ahmad MQ, Yang SH, Lee SI. Comparative genomic and transcriptomic analyses of Family-1 UDP glycosyltransferase in three Brassica species and Arabidopsis indicates stress-responsive regulation. Sci Rep. 2018;8:1875.

104. Bach TJ. Some new aspects of isoprenoid biosynthesis in plants - a review. Lipids. 1995;30:191-202.

105. Posé D, Castanedo I, Borsani O, Nieto B, Rosado A, Taconnat L, Ferrer A, Dolan L, Valpuesta V, Botella MA. Identification of the Arabidopsis dry2/ sqe1-5 mutant reveals a central role for sterols in drought tolerance and regulation of reactive oxygen species. Plant J. 2009;59:63-76.

106. Schoen DJ, Brown AH. Conservation of allelic richness in wild crop relatives is aided by assessment of genetic markers. Proc Natl Acad Sci U S A. 1993; 90:10623-7.

107. Gouesnard B, Bataillon TM, Decoux G, Rozale C, Schoen DJ, David JL. MSTR AT: an algorithm for building germ Plasm Core collections by maximizing allelic or phenotypic richness. J Hered. 2001;92:93-4.

108. Nei L. Molecular evolutionary genetics. New York: Columbia University Press; 1987.

109. Kimura M, Crow JF. The number of alleles that can be maintained in a finite population. Genetics. 1964;49:725-38.

110. Nei M. Analysis of gene diversity in subdivided populations. Proc Natl Acad Sci U S A. 1973;70:3321-3.

111. Wright $\mathrm{S}$. The interpretation of population structure by F-statistics with special regard to systems of mating. Evolution. 1965;19:395-420.

112. Peakall R, Smouse PE. Genalex 6: genetic analysis in excel. Population genetic software for teaching and research. Mol Ecol Note. 2006;6:288-95.

113. Pritchard JK, Stephens M, Donnelly P. Inference of population structure using multilocus genotype data. Genetics. 2000;155:945-59.

114. Falush D, Stephens M, Pritchard JK. Inference of population structure using multilocus genotype data: linked loci and correlated allele frequencies. Genetics. 2003;164:1567-87.

115. Earl DA, von Holdt BM. STRUCTURE HARVESTER: a website and program for visualizing STRUCTURE output and implementing the Evanno method. Conservation Genet Resour. 2012:4:359-61.

116. Jakobsson M, Rosenberg NA. CLUMPP: a cluster matching and permutation program for dealing with label switching and multimodality in analysis of population structure. Bioinformatics. 2007;23:1801-6.

117. Rosenberg NA. DISTRUCT: a program for the graphical display of population structure. Mol Ecol Notes. 2004;4:137-8.

118. Jombart T, Devillard S, Balloux F. Discriminant analysis of principal components: a new method for the analysis of genetically structured populations. BMC Genet. 2010;11:94

119. Kamvar ZN, Brooks JC, Grünwald NJ. Novel R tools for analysis of genomewide population genetic data with emphasis on clonality. Front Genet. 2015;6:208.

120. Black CA. Methods of soil analysis: part I, physical and mineralogical properties. Madison, Wisconsin: American Society of Agronomy; 1965. p. 197-209.

121. Idso SB, Jackson RD, Pinter PJ, Reginato RJ, Hat eld JL. Normalizing the stress-degree-day parameter for environmental variability. Agric Meteorol. $1981 ; 24: 45-55$

122. Jones $\mathrm{HG}$. Use of infrared thermometry for estimation of stomatal conductance as a possible aid to irrigation scheduling. Agric For Meteorol. 1999:95:139-49.

123. Bradbury PJ, Zhang Z, Kroon DE, Casstevens TM, Ramdoss Y, Buckler ES. TASSEL: software for association mapping of complex traits in diverse samples. Bioinformatics. 2007;19:2633-5.

124. Yu J, Pressoir G, Briggs WH, Vroh Bi I, Yamasaki M, Doebley JF, McMullen MD, Gaut BS, Nielsen DM, Holland JB, Kresovich S, Buckler ES. A unified mixed-model method for association mapping that accounts for multiple levels of relatedness. Nat Genet. 2006;38:203-38.

125. Endelman JB, Jannink JL. Shrinkage Estimation of the Realized Relationship Matrix. G3-Genes Genom Genet. 2013;2:1405-13.

126. Benjamini $Y$, Hochberg Y. Controlling the false discovery rate: a practical and powerful approach to multiple testing. J R Stat Soc. 1995;57:289-300.

127. Benjamini Y, Yekutieli D. Quantitative trait loci analysis using the false discovery rate. Genetics. 2005;171:783-90.

128. Turner SD. qqman: an R package for visualizing GWAS results using QQ and Manhattan plots. bioRxiv. 005165. https://doi.org/10.1101/005165.2014
129. Vitulo N, Forcato C, Carpinelli EC, Telatin A, Campagna D, D'Angelo M Zimbello R, Corso M, Vannozzi A, Bonghi C, Lucchin M, Valle G. A deep survey of alternative splicing in grape reveals changes in the splicing machinery related to tissue, stress condition and genotype. BMC Plant Biol. 2014;14:99.

130. Rozen S, Skaletsky HJ. Primer3 on the WWW for general users and for biologist programmers. Methods Mol Biol. 2000;132:365-86.

131. Emanuelli F, Battilana J, Costantini L, Le Cunff L, This P, Grando MS. A candidate gene association study for Muscat flavor in grapevine (Vitis vinifera L.). BMC Plant Biol. 2010;10:241.

132. Librado P, Rozas J. DnaSP v5: a software for comprehensive analysis of DNA polymorphims data. Bioinformatics. 2009;25:1451-2.

133. Nei M, Li WH. Mathematical model for studying genetic variation in terms of restriction endonucleases. Proc Natl Acad Sci U S A. 1979;76:5269-73.

134. Watterson GA. On the number of segregation sites. Theor Pop Biol. 1975;7: 256-76.

135. Tajima F. Statistical method for testing the neutral mutation hypothesis by DNA polymorphism. Genetics. 1989;123:585-95.

136. Fu YX, Li WH. Statistical tests of neutrality of mutations. Genetics. 1993;133: 693-709.

137. Choi Y, Chan AP. PROVEAN web server: a tool to predict the functional effect of amino acid substitutions and indels. Bioinformatics. 2015;31:27457.

138. Hellemans J, Mortier G, De Paepe A, Speleman F, Vandesompele J. qBase relative quantification framework and software for management and automated analysis of real-time quantitative PCR data. Genome Biol. 2007:8: R19.

\section{Publisher's Note}

Springer Nature remains neutral with regard to jurisdictional claims in published maps and institutional affiliations.
Ready to submit your research? Choose BMC and benefit from:

- fast, convenient online submission

- thorough peer review by experienced researchers in your field

- rapid publication on acceptance

- support for research data, including large and complex data types

- gold Open Access which fosters wider collaboration and increased citations

- maximum visibility for your research: over $100 \mathrm{M}$ website views per year

At BMC, research is always in progress.

Learn more biomedcentral.com/submission 